TITLE:

\title{
Formation and Reduction Processes of River Deltas; Theory and Experiments
}

$\operatorname{AUTHOR}(S)$ :

REFAAT, Hossam El-din A.A.; TSUCHIYA, Yoshito

\section{CITATION:}

REFAAT, Hossam El-din A.A. ... [et al]. Formation and Reduction Processes of River Deltas; Theory and Experiments. Bulletin of the Disaster Prevention Research Institute 1991,

41(3): $177-224$

ISSUE DATE:

1991-09

URL:

http://hdl.handle.net/2433/124979

RIGHT: 


\title{
Formation and Reduction Processes of River Deltas; Theory and Experiments
}

\author{
By Hossam El-din A. A. ReFAAT ${ }^{i}$ and Yoshito TsuchiYA
}

(Manuscript received on July 17, 1991; revised on Nov. 25, 1991)

\begin{abstract}
Beach erosion has recently been recognized as accelerating due to changes in sediment sources from rivers. This can be considered as reduction processes of river deltas. In this paper, the formation and reduction processes of river deltas are first investigated theoretically by introducing the non-uniformity of longshore sediment transport into the equation of continuity of shoreline change. Theoretical solutions to shoreline changes in the formation and reduction processes are derived from the simplified governing equations using the concept of one-line theory. By numerical results of the solutions, shoreline changes in the formation and reduction processes are well explained. Secondly, experiments both on the formation and reduction processes were carried out. The theoretical results of the processes compared favorably with the experimental ones, indicating that the processes can be well explained by specifying the predominant parameters.
\end{abstract}

\section{Introduction}

Deltas result from the relative extent of deposition of river sediments which build the delta seaward, versus the action of waves and currents which transport the sediments. Historically, the term delta was first applied by the Greek historian Herodotus, circa 450 B. C., to the triangular alluvial deposit at the river mouth of the Nile River. Deltas may be formed wherever a stream debouches into an ocean, gulf, inland sea, bay, or lake. Consequently, deltas of various size and shape can be found throughout the world. The river delta areas have been recognized as a natural site for human activities, particularly in those civilizations with great cultural environment as economic activities. The coasts of river delta have generally been developed for agriculture, industry, residential areas, and recreational usages. In recent years development and utilization of coastal areas have steadily increased. Development of the coastal areas and river basins has frequently resulted in severe beach erosion particularly due to the construction of river dams which intercept the sediment input from the river to the coast.

The river deltas are mainly categorized as : 1) river-dominated type in which the river sediment discharge (input of sediment from the river) is predominant and wave energy

1 Research Fellow on leave from Faculty of Engineering, Cairo University, Giza, Egypt 
is minimal, 2) wave-dominated type which represents higher wave energy situations, and 3) tide-dominated type where the tidal currents impinge on coastal waters near river deltas and cause river discharged sediments to be transported and dispersed along the coast at considerable distances from the river mouth.

The formation and reduction processes of river deltas in 1) and 2) are generally governed by the interaction between two main forces; river sediment discharge and wave energy. If the rate of sediment deposition from the river is greater than the rate of sediment removal by the longshore currents, the formation process of river delta will take place. On the contrary, if the rate of sediment deposition from the river is less than the rate of sediment removal by the longshore currents, beach erosion occurs resulting in the reduction of river delta. Generally speaking, the formation and reduction of river deltas can be determined by the relation between the sediment deposition during annual floods from the river which build the delta seaward and the longshore sediment transport rate by the action of waves and currents which transport the sediments alongshore.

The processes of formation and reduction of river deltas have often been investigated through the study of analytical solutions of the so-called one-line theory which is derived from the simplified problem. The analytical solutions which only describe the symmetrical plane geometry of river deltas formed by normally incident waves can be considered as a starting point for the understanding of the formation process of river deltas. By use of the one-line theory, therefore, such analytical solutions have to be improved enabling the estimation of the plane geometry of river deltas by obliquely incident waves and enhancing their applicability.

\subsection{The so-called one-line theory for shoreline change}

The one-line theory for shoreline change prediction was first introduced by PelnardConsidére (1956), and it has been demonstrated to be adequate in practical applications. Several authors have presented analytical solutions for the one-line theory (e.g. Bakker and Edelman, 1964; Iwagaki, 1966; Tsuchiya, 1973, 1978; Bakker, 1968; Le Méhauté and Soldete, 1979; Walton and Chiu, 1979; and Tsuchiya and Yasuda, 1979). However, to describe more realistic situations involving general shoreline configurations, together with time varying wave conditions, the one-line theory has been implemented using numerical techniques (e.g. Price, Tomlinson and Willis, 1972; Sasaki and Sakuramoto, 1978 ; Kraus, Hanson and Harikai, 1985 ; and Hanson and Larson, 1987).

The aim of the one-line theory is to describe long-term variation in shoreline. Shortterm variations (e. g., changes caused by storms) are regarded as negligible perturbations superimposed on the main trend of shoreline evolution. This is because the beach profile and shoreline position which experience dramatic changes due to severe storms often return to their pre-storm profiles after the storms have passed. In contrast, imbalance in the longshore sediment transport rate cause more gradual and permanent changes in beach configuration. By this process, the beach profiles appear to remain essentially unchanged, and the time scale involved is normally in the order of years. Based on the observation that the beach profile is assumed to be relatively stable in a long-term perspective, Pelnard-Considére (1956) formulated what was later called the one-line theory. 
The fundamental assumption of this theory is that erosion or accretion of a beach results in a pure translation of the beach profile. Thus, the bottom profile moves in parallel to itself without changing shape. The second major assumption of the theory is that the longshore sediment transport takes place averaging over the beach profile down to a certain offshore limiting depth of the sediment drift zone, called the critical depth for sediment movement by waves. No sediment is presumed to move longshore in the region seaward of this depth, thus beyond this depth the sea bottom does not move.

\subsection{Previous investigations of formation and reduction processes of river deltas}

Pelnard-Considére (1956) first proposed a mathematical model as described above. He derived analytical solutions of diffusion type equations for three different boundary conditions : the shoreline evolution upstream of a groin (with and without bypassing) and the release of an instantaneous plane source of sand on the beach.

Grijm (1961) studied the formation of river deltas where the rate of longshore sediment transport is assumed to be proportional to twice the incident breaking wave angle to the shoreline. Only solutions which were similar in shape during the course of time were discussed. Two different analytical solutions were presented: one for which both the incident breaking wave angle and the shoreline orientation angle are small and the other for which the wave angle is small in comparison with the shoreline orientation. The governing equations of shoreline change, which are composed of the equations of longshore sediment transport and continuity of shoreline change, were expressed in the polar coordinates and solved numerically. Grijm (1964) further developed this technique and presented a wide range of delta formations, but only for the formation of symmetrical river deltas due to normally incident waves. No formulation of the formation of deltas by obliquely incident waves has been made.

Le Méhauté and Brebner (1961) discussed solutions for shoreline change by groins, with and without bypassing of sand, and the effect of sudden dumping of material at a given point. Most of the solutions were previously derived by Pelnard-Considére (1956), but they are more precisely presented in their work, especially regarding geometric aspects of the shoreline change. The decay of an oscillating shoreline and the equilibrium shape of the shoreline between two headlands were treated. Bakker and Edelman (1964) treated the shape of river delta by modifying the equation of longshore sediment transport rate to allow for an analytical treatment without linearization. Their solutions may be more or less similar to Grijm's work.

Bakker (1968) extended the one-line theory available to describe beach profile change. The beach profile is divided into two parts, one relating to shoreline movement and the other to movement of an offshore contour. The two lines in the model are represented by a system of two differential equations which are coupled through a term describing cross-shore transport. According to him, the cross-shore transport rate depends on the steepness of the beach profile, a steep profile implies offshore sand transport, and a gently sloping profile implies onshore sand transport. However, the analytical solutions on the two-line theory will not be included in the present study.

Tsuchiya (1973) derived analytical solutions for predicting shoreline changes around 
river mouths. By expressing the sediment input from a river by Dirac's delta function, he could produce a modified model of the one-line theory. Komar (1973) also numerically presented solutions of delta growth under highly simplified conditions. Tsuchiya and Yasuda (1979) further extended the analytical solutions for predicting shoreline changes around a groin and a river delta by introducing a new formulation for the rate of longshore sediment transport. In their study, an extension of this formulation is made to include the non-uniformity of the longshore sediment transport. They also discussed analytical solutions for shoreline changes for a groin of finite length, in which part of longshore sediment transport is entrapped, and for a river delta, of which the rate of sediment input from a river is varied. In their formulation, however, nonuniformity of longshore sediment transport is too simply introduced to be able to solve these problems.

Le Méhauté and Soldate (1979) presented a brief literature survey on the subject of mathematical modeling of shoreline evolution. Analytical solutions of the linearized equation of shoreline change were discussed along with the dispersion of sediment in a rectangular beach fill. A numerical model was derived which included variation in sea level, wave refraction and diffraction, rip currents, and the effects of coastal structures in connection with long-term shoreline evolution. But no formulation of river delta formation was made. The most complete summary of analytical solutions to the sediment transport equation has been made by WaIton and Chiu (1979). Two derivations of the continuity equation of sediment transport are presented. The differences between these two approaches, from which both arrived at diffusion type equations, are that one approach uses the Coastal Engineering Research Center (CERC) formula for describing the longshore sediment transport rate by wave action and the other uses the formula derived by Dean (1973) based on the assumption that the majority of sediment transport occurs as suspended load. Additional solutions mainly concern beach nourishment in connection with various shoreline shapes. New solutions derived by them treat beach fill in a triangular shape, a rectangular gap in a beach, and a semi-infinite rectangular fill. Dean (1984) gives a brief survey of some solutions applicable to beach nourishment calculations, especially in the form of characteristic quantities describing loss percentages. One solution describes the shoreline change between two groins initially filled with sand, but with no river delta formation.

Recently, Hanson and Larson (1987) proposed an analytical solution solution and two different numerical formulations. A comparison between these two solutions has been made based on the capabilities and limitations of each method through the study of shoreline evolution for a simple shoreline-structure configuration under idealized wave conditions.

As discussed in the previous investigations of the formation and reduction processes of river deltas, the formation process by normally incident waves can be explained by the one-line theory for shoreline change, but the effects of oblique incident waves have not been solved yet. This formation process may be due to the longshore sediment transport under nonuniform conditions. In this paper, therefore, introducing the nonuniformity of longshore sediment transport, a theory of the formation of river delta by normally or obliquely incident waves is first proposed. Numerical calculation of the river delta forma- 
tion was performed to consider the formation processes theoretically. Secondly, a theory of the reduction process of river deltas is also proposed, and the theoretical reduction process is investigated numerically. In order to verify these theoretical solutions, experiments were carried out on these formation and reduction processes of river deltas by normally and obliquely incident waves. The physical processes of river delta formation and reduction are then considered, and the experimental results are compared with the theoretical solutions for agreement.

\section{Theory of the Formation and Reduction Processes of River Deltas}

In the previous section the fundamentals of one-line theory were discussed. The fundamental assumption of the theory, that the beach profile does not change, may only be applied for predicting the shoreline evolution of river deltas of wave-dominated delta type. If an improvement of the theory is made by introducing the nonuniformity of longshore sediment transport, the shoreline evolution of the river delta can be predicted analytically.

In the formation and reduction processes of river deltas, the nonuniformity of longshore sediment transport along the shoreline must be introduced in the theoretical formulation. To introduce the nonuniformity of longshore sediment transport, two ways may be considered: one is to establish an equation of longshore sediment transport in the nonuniform condition, and the other is to reconsider the geometry of shoreline change in relation to change of the breaker line, which may influence the nonuniformity of longshore sediment transport. Tsuchiya and Refaat (1992) recently developed theoretical approaches to the longshore sediment transport in the nonuniform condition. Introducing this theoretical formulation of the total rate of nonuniform longshore sediment transport, a set of the governing equations of shoreline change is proposed. And in the geometrical change of shoreline, changes in breaker angle and depth are also introduced in the formulation to propose a theory of formation and reduction processes of river deltas by normally and obliquely incident waves, respectively.

\subsection{The governing equations and the equations of delta formation process}

The equations governing the formation and reduction processes of river deltas are comporsed of the equations of continuity of shoreline change and total rate of longshore sediment transport. Iwagaki (1966) derived the equation of continuity of shoreline change by integrating the equation of continuity of sediment transport over the whole range of sand drift in the surf zone, and Tsuchiya (1973, 1978) modified this equation by expressing the sediment input from a river by Dirac's delta function and reconsidering the concept of the one-line theory for shoreline change. Taking the coordinate system as shown in Fig. 1, the equation of continuity of shoreline change is expressed as:

$$
\frac{\partial y_{0}}{\partial t}+\frac{1}{(1-\lambda) h_{k}} \frac{\partial Q_{x}}{\partial x}=\frac{1}{B h_{k}} Q_{R}(t) \delta\left(x-x_{0}\right)
$$




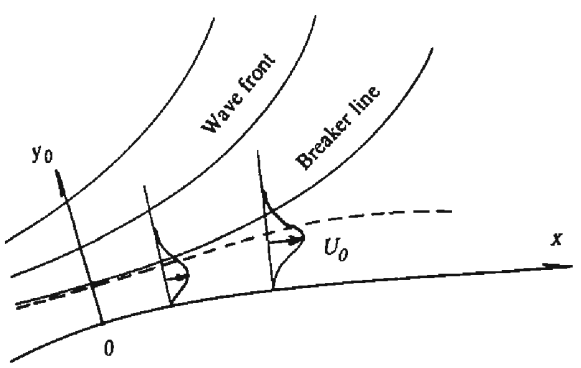

(a) Coordinate system and longshore current

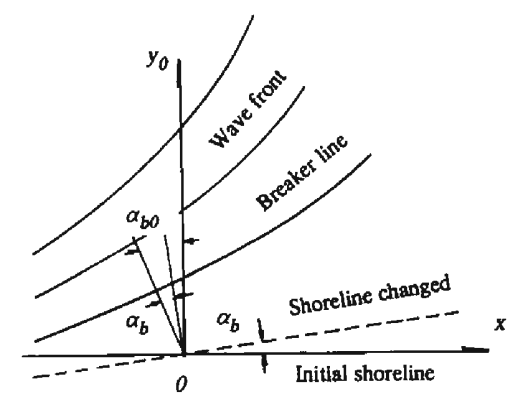

(b) Changes of shoreline and breaker angle

Fig. 1. The coordinate system used in the formulation.

in which $y_{0}$ is the shoreline position from the datum line and taken positive offshoreward, $x$ is the longshore distance from the origin, $t$ is the time, $\lambda$ is the porosity of beach sediment (approximately 0.4 for most beach deposits), $h_{k}$ is the limiting water depth of littoral drift, $B$ is the river width, $Q_{x}$ is the total rate of longshore sediment transport, and $Q_{R}(t) \delta\left(x-x_{0}\right)$ is the sediment input effective to the shoreline change from a river located at $x=x_{0}$ where $\delta\left(x-x_{0}\right)$ is Dirac's delta function.

Usually, the longshore sediment transport formula has been used in the formation of one-line theory for shoreline change, by introducing it into the equation of continuity, Eq. (1). However, this formula may be applicable only to the uniform or quasi-uniform conditions of longshore sediment transport because it was derived in the uniform longshore condition. The phenomenon of longshore sediment transport around the river deltas are nonuniform owing to the non-uniform characteristics of waves and the effect of the boundary conditions of both longshore currents and beach changes on the longshore sediment transport. In the formulation of the formation and reduction processes of river deltas, each circumstance of nonuniform longshore sediment transport must be introduced. River deltas are asymmetrically formed by obliquely incident waves. The formation process may be solved by introducing the nonuniform longshore sediment transport along the shoreline of the river delta. Tsuchiya and Refaat (1990) recently derived an equation for nonuniform longshore currents by introducing the method of the boundary layer into the equations of nearshore currents and integrating them over the whole area in the surf zone. The relationship between the total rate of longshore sediment transport and and the longshore current velocity is given by Tsuchiya (1980) as :

$$
Q_{x}=k h_{b}^{2} U_{o} \text { where } k=\frac{c_{o}}{m}\left(\frac{\rho}{\sigma}\right) I\left(R, F_{r}\right)
$$

where $Q_{x}$ is the total rate of longshore sediment transport, $c_{o}$ the averaged sediment concentration being nearly 0.2 although it varies slightly with Shields parameter, $m$ the beach slope, $\sigma / \rho$ the specific gravity of sediment, $h_{b}$ the breaker water depth, $U_{0}$ the 
nominal longshore current velocity at the breaking point, and $I\left(R, F_{r}\right)$ the function of the dimensionless properties of breakers and sediment. The equation of nonuniform longshore currents is given by Tsuchiya and Refaat (1990) as :

$$
\frac{\partial}{\partial t}\left(h_{b}^{2} U_{o}\right)+\left(\frac{\alpha_{2}}{\alpha_{1}}\right) \frac{\partial}{\partial x}\left(h_{b}^{2} U_{o}^{f}\right)=f(x)-\left(\frac{\alpha_{3}}{\alpha_{1}}\right) \frac{\gamma C_{f}}{\pi} \sqrt{g h_{b}} h_{b} U_{o}
$$

where

$$
\begin{aligned}
f(x)=\frac{\gamma^{2}}{16 \alpha_{1}} g h_{b}^{2} & {\left[\sin 2 \alpha_{b}-2 \cos ^{2} \alpha_{b} \frac{\partial y_{b}}{\partial x}\right.} \\
& \left.-\left(5 \beta_{1}-6 \beta_{2}+6 \beta_{3} \sin ^{2} \alpha_{b}\right) \frac{\partial h_{b}}{\partial x}-2 \beta_{2} h_{b} \sin 2 \alpha_{b} \frac{\partial \alpha_{b}}{\partial x}\right]
\end{aligned}
$$

where $\alpha_{b}$ is the breaker angle which is defined as the angle between the wave crest and the shoreline, $t$ the time, $\mathrm{g}$ the acceleration of gravity, $y_{b}$ the offshore distance of the breaking point from the shoreline, $\alpha_{t}$ and $\beta_{i}(i=1,2,3)$ are the coefficients being nearly constants (Tsuchiya and Refaat, 1992). Inroducing Eq. (2) into Eq. (3) the equation of longshore sediment transport in the unsteady, nonuniform condition is obtained as :

$$
\frac{\partial Q_{x}}{\partial t}+\frac{a_{2}}{\alpha_{1} k} \frac{\partial}{\partial x}\left(\frac{Q_{x}}{h_{b}}\right)=k f(x)-\frac{a_{3} \sqrt{g} \gamma C_{f}}{\alpha_{1} \sqrt{h_{b}}} Q_{x}
$$

Under the assumption that any small change in shoreline is only considered in the case where the breaker angle is assumed to be considerably small, as shown in Fig. 1, Eq. (4) may be approximated as :

$$
f(x)=\frac{\gamma^{2}}{16 \alpha_{1}} g h_{b}^{2}\left[\sin 2 \alpha_{b o}-m\left(4+5 \beta_{1}-6 \beta_{2}+6 \beta_{3} \sin ^{2} \alpha_{b o}\right) \frac{\partial y_{a}}{\partial x}-2 \beta_{2} h_{b} \sin 2 \alpha_{b 0} \frac{\partial^{2} y_{0}}{\partial x^{2}}\right]
$$

where $a_{b o}$ is the breaker angle at the beginning of shoreline change.

In order to formulate the formation process of river delta, both equations of continuity of shoreline change, Eq. (1), and of nonuniform longshore sediment transport rate, Eq. (5), must be reduced to the equation of river delta formation process. If the first and second terms on the left hand side of Eq. (5) are small compared with the other two terms, introducing the equation into Eq. (1), where the sediment input from the river is omitted, and neglecting small terms in the formulation finally yields

$$
\frac{\partial y_{0}}{\partial t}+\frac{\gamma m k}{16(1-\lambda) \alpha_{3} C_{f}} \sqrt{g h_{b}}\left[\left(\frac{5}{2} \sin 2 \alpha_{b 0}+2 \cos 2 \alpha_{b 0}\right) \frac{\partial y_{0}}{\partial x}\right.
$$




$$
\left.-\left(4+5 \beta_{1}-6 \beta_{2}+6 \beta_{3} \sin ^{2} \alpha_{b 0}\right) h_{b} \frac{\partial^{2} y_{0}}{\partial x^{2}}-2 \beta_{2} \sin 2 \alpha_{b 0} h_{b}^{2} \frac{\partial^{3} y_{0}}{\partial x^{3}}\right]=0
$$

which is one of the diffusion type equations having first and third order derivatives. It is therefore recognized that formation process of river deltas, if it is considered as one of the natural diffusion phenomena, can be considered by solving Eq. (7) under the initial and boundary conditions, as well as the condition of sediment input from a river. And if the second term, being the only nonlinear term on left hand side, is omitted, the equation becomes

$$
\frac{\partial Q_{x}}{\partial t}=k f(x)-\frac{\alpha_{3} \sqrt{g} \gamma C_{f}}{a_{1} \sqrt{h_{b}}} Q_{x}
$$

The set of the above equation of longshore sediment transport and the equation of continuity, Eq. (1) can be solved under the initial and boundary conditions. It may be noted that by the set of the equations, the process of shoreline change, which may correspond to shoreline changes in the beach erosion due to lack of longshore sediment transport, can be considered as a kind of kinematic wave propagation.

In order to obtain the diffusion equation for the formation process of river deltas, the usual method can be applied by assuming that small shoreline changes produce small changes in the breaker height and angle. In the usual method, however, changes in breaker angle by changing the shoreline orientation are only considered in the formulation of total rates of longshore sediment transport, but, in this paper, changes in breaker water depth in the longshore direction is taken into account in the derivation of the diffusion equation. Thus, in order to express the total rate of longshore sediment transport by a function of the breaker height and water depth and their derivatives, it can be expressed by Taylor series up to the first order as :

$$
Q_{x}\left(a_{b}, h_{b}\right)=Q_{o}+\frac{\partial Q_{x}}{\partial a_{b o}}\left(\alpha_{b}-\alpha_{b o}\right)+\frac{\partial Q_{x}}{\partial \bar{h}_{b o}}\left(h_{b}-h_{b o}\right)+\ldots \ldots
$$

where $Q_{o}$ denotes the total rate of longshore sediment transport at the initial wave conditions presented by the subscript $o$. Referring to Fig. 1 the small changes in the breaker water depth and angle can be expressed geometrically as:

$$
\frac{\partial \alpha_{b}}{\partial x} \approx \frac{\partial y_{o}}{\partial x} \text { and } \frac{\partial h_{b}}{\partial x} \approx m \frac{\partial y_{o}}{\partial x}
$$

Substituting Eqs. (9) and (10) to Eq. (1) yields

$$
\frac{\partial y_{o}}{\partial t}+\varepsilon_{1} \frac{\partial y_{o}}{\partial x}-\varepsilon_{2} \frac{\partial^{2} y_{o}}{\partial x^{2}}=q_{R}(t) \delta\left(x-x_{o}\right)
$$


where

$$
\begin{aligned}
& \varepsilon_{1}=\frac{m}{(1-\lambda) h_{k}}\left[\frac{\partial Q_{x}}{\partial h_{b}}\right]_{h_{b o}} \text { and } \varepsilon_{2}=\frac{1}{(1-\lambda) h_{k}}\left[\frac{\partial Q_{x}}{\partial \alpha_{b}}\right]_{a_{b o}} \\
& q_{R}(t)=\frac{1}{B h_{k}} Q_{R}(t)
\end{aligned}
$$

Eq. (12) is of course identical to the one-dimensional equation of diffusion type described as a linear partial differential equation which may be practically the same as Eq. (7) if the third order partial derivative term is ignored. It is also noted in this formulation that the second term of a first order derivtive on the left exists to possibly show asymmetiric formation of a river delta when obliquely incident waves approach the beach. When the shoreline gently changes along the coast of a river delta and the waves approach the beach nearly normally, the coefficient becomes very small and can be ignored. In other words, neglecting the second term, Eq. (12) is reduced to a diffusion equation, which may only show a symmetrical solution for the evolution of river deltas. The coefficient $\varepsilon_{2}$, which has the dimensions of length squared over time, is interpreted as a diffusion coefficient. While the coefficient $\varepsilon_{1}$, having the dimension of length over time, is interpreted as the traveling speed of shoreline towards the longshore direction. In Eq. (12), it is clearly seen that the coefficient $\varepsilon_{1}$ is proportional to the beach slope. Thus, the coefficient $\varepsilon_{1}$ can not be ignored when the beach slope changes along the coast of a river delta, as in the case of the river-dominated delta type where the beach slope at the river mouth is steeper than the beach slope at the alongshore ends of the river delta.

Now the linear partial differential equation presented by Eq. (12) can be transformed to the diffusion type equation by substituting

$$
y_{0}=z_{0} \exp \left(\frac{\varepsilon_{1}}{2 \varepsilon_{2}} x-\frac{\varepsilon_{1}^{2}}{4 \varepsilon_{2}} t\right)
$$

into Eq. (12), to reduce

$$
\frac{\partial \mathrm{z}_{0}}{\partial t}=\varepsilon_{2} \frac{\partial^{2} z_{0}}{\partial x^{2}}+q_{R}(t) \delta\left(x-x_{0}\right) \exp \left(-\frac{\varepsilon_{1}}{2 \varepsilon_{2}} x+\frac{\varepsilon_{1}^{2}}{4 \varepsilon_{2}} t\right)
$$

By specifying the initial and boundary conditions in the areas which represent conditions prevailing in a specific shoreline evolution, the analytical solutions are directly applicable.

\section{2 Solution to shoreline changes in the formation process of river deltas by normally incident}

waves

The equation of shoreline changes in the formation process of river deltas by normally incident waves is of course Eq. (12) to be solved with the associated initial and 
boundary conditions. An infinitely long beach exposed to waves of constant properties is assumed. If the river mouth is small in comparison with the area into which sediment input is given from a river, the river sediment input may be assumed as a point source. Also, if $y_{0}=0$ at $t=0$ as the boundary condition, the general solution of river delta formation can be expressed from Eq. (12) (Carslaw and Jaeger, 1959) as :

$$
y_{o}(x, t)=z_{o}(x, t) \exp \left[\left(\frac{\varepsilon_{1}}{2 \varepsilon_{2}}\right) x-\left(\frac{\varepsilon_{1}}{4 \varepsilon_{2}}\right) t\right] \text { for } t \geq 0 \text { and }-\infty \leq x \leq \infty
$$

where

$$
z_{o}(x, t)=\frac{1}{2 \sqrt{\pi \varepsilon_{2}}} \int_{0}^{t} \frac{q_{R}\left(t^{\prime}\right) \delta\left(x-x_{o}\right)}{\sqrt{\left(t-t^{\prime}\right)}} \exp \left[-\frac{\left(x-x_{0}\right)^{2}}{4 \varepsilon_{2}\left(t-t^{\prime}\right)}-\frac{\varepsilon_{1}}{2 \varepsilon_{2}} x+\frac{\varepsilon_{1}^{2}}{4 \varepsilon_{2}}(t-t)\right] d t
$$

Consequently, applying the general solution the configuration of the shoreline of river delta can be determined under the given initial and boundary conditions. Analytical solutions in various simplified conditions of river deltas will be derived mostly from Eq. (16) by Laplace transformation.

\section{(1) The formation of river delta of infinite length}

Since normally incident waves are assumed, the configuration of river delta will be symmetrical with respect to the point source. If the river delta is exposed to a strong wave field as the so-called wave-dominated river delta, the shoreline will change gently along the coast of the delta. Therefore the coefficient $\varepsilon_{1}$ becomes very small and can be neglected. When the sediment input from the river is constant, being $q_{R 0}$, the solution derived from Eq. (16) is given as :

$$
y_{o}(x, t)=h_{k} q_{R o} \sqrt{\frac{t}{\varepsilon_{2}}} \operatorname{jerfc}\left(\frac{\left|x-x_{0}\right|}{2 \sqrt{\varepsilon_{2} t}}\right) \text { for } t \geq 0 \text { and }-\infty \leq x \leq \infty
$$

where jerfc denotes the integral of the complementary error function erfc which is expressed as :

$$
\text { jerfc } \omega=\int_{\omega}^{\infty} \operatorname{erfc} \zeta d \zeta
$$

In Fig. 2 the solution to Eq. (18) is illustrated. The shoreline position is normalized by the limiting water depth of littoral drift, $h_{k g}$ while the longshore distance is normalized by $h_{k}$. Since the configuration of river delta is symmetric, only a half of the delta plane shape is shown in the figure where the dimensionless sediment input used to normalize the shoreline position is expressed as : 


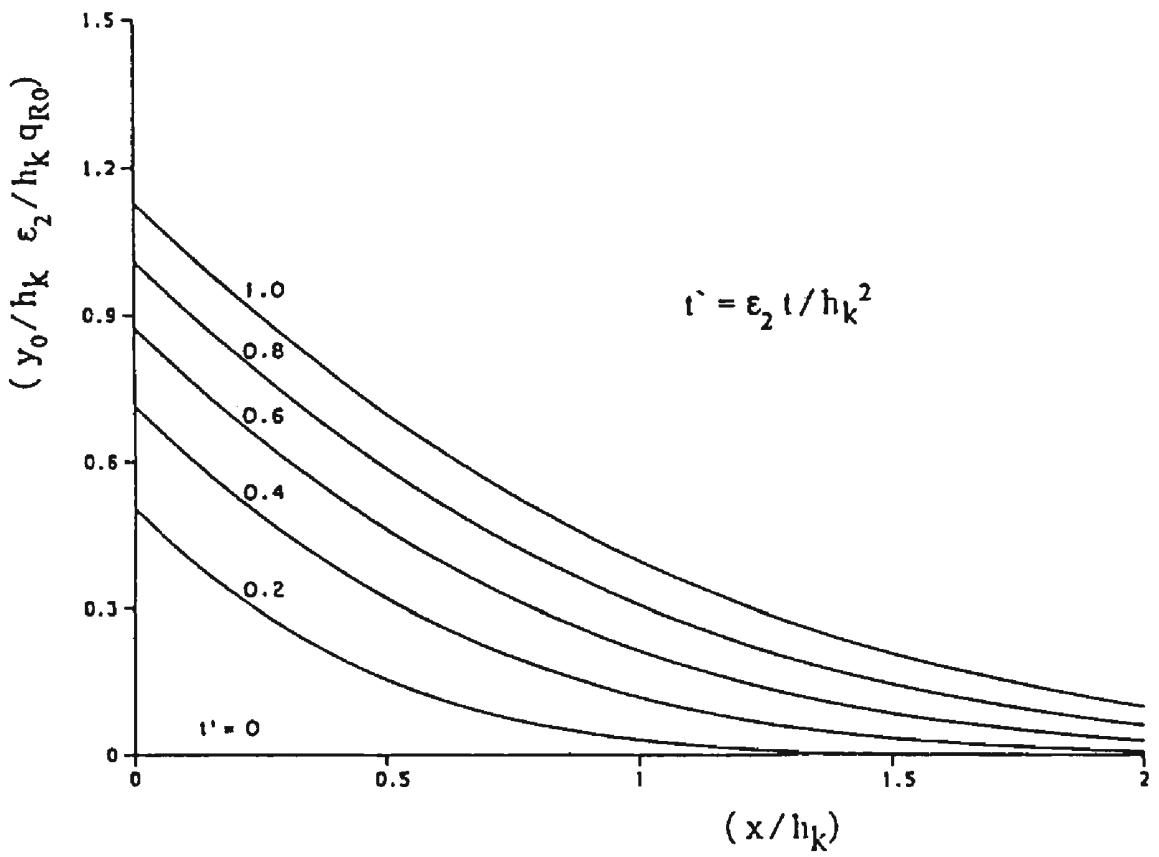

Fig. 2. Shoreline evolution in the formation of river delta of infinite length.

$$
\frac{h_{k} q_{R o}}{\varepsilon_{2}}=\frac{q_{R o}}{\left(\partial Q_{x} / \partial a_{b}\right)_{a_{b o}}}
$$

which can be interpreted as a ratio of the sediment input from the river to the derivative of longshore sediment transport rate with respect to the breaker angle. The time required for the delta formation to reach a certain distance $y_{0}$ from the original shoreline position is calculated by :

$$
t=\frac{\pi \varepsilon_{2}}{\left(h_{k} q_{R o}\right)^{2}} y_{o}^{2}
$$

The above equation is also illustrated in Fig. 3 in a dimensionless expression. For a specific wave climate, the above relation implies that an increase in sediment input has a proportional effect on the growth of the delta as :

$$
\frac{y_{o 1}}{y_{o 2}}=\frac{q_{R 1}}{q_{R 2}}
$$

where the indices 1 and 2 refer to two different conditions of sediment input exposed to 


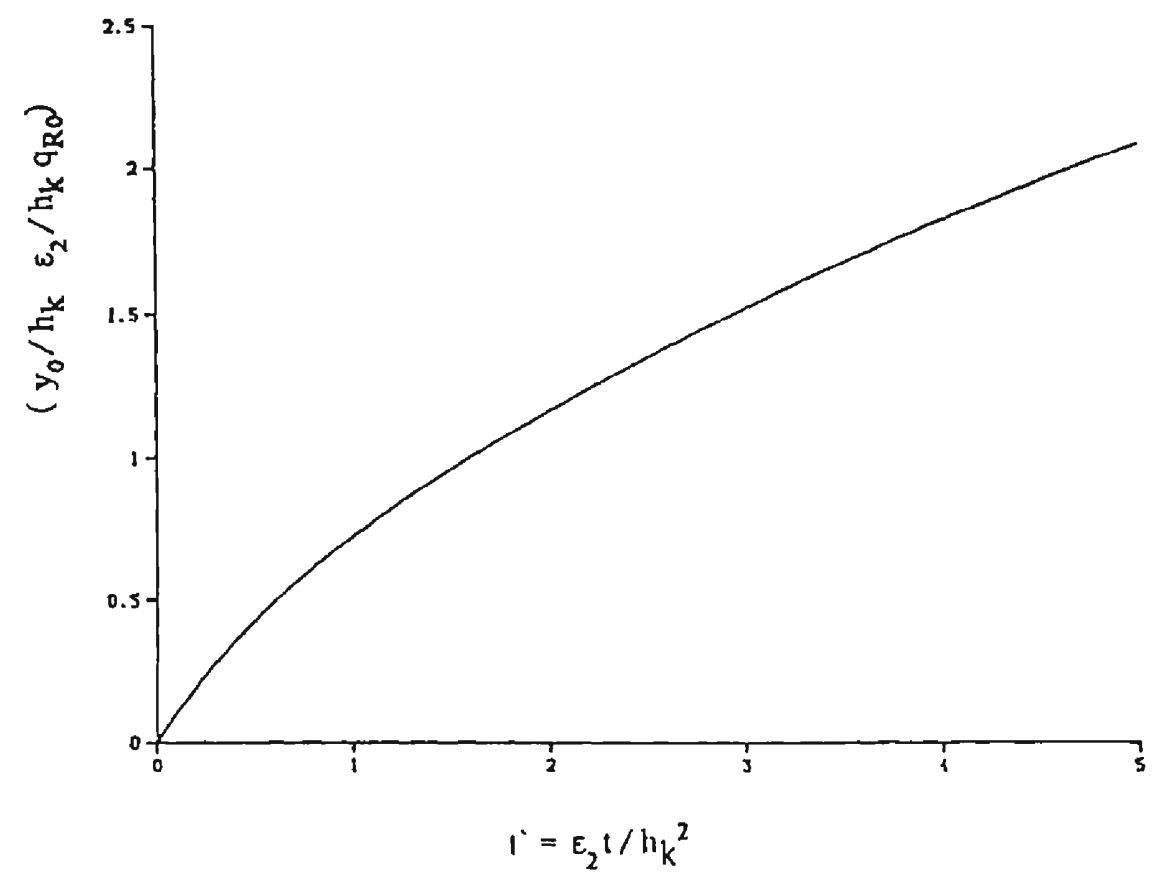

Fig. 3. Time variation of shoreline change at the center of a river delta of infinite length.

the same wave climate.

(2) The formation of river delta of finite river mouth

If the river mouth has a finite width, an approximation by a point source is no longer accurate. Instead of the sediment input to the beach via the delta function, the continuity equation of sediment transport will be applied twice, once over the river mouth where $q_{R o}$ is assumed to be uniformly distributed along the river mouth of a width $2 a$, and once outside the river mouth where $q_{R o}$ is no longer considered. Mathematically, the situation can be expressed as :

$$
\frac{\partial y_{01}}{\partial t}=\varepsilon_{2} \frac{\partial^{2} y_{01}}{\partial x^{2}}+q_{R 0} ;-a \leq x \leq a
$$

and

$$
\frac{\partial y_{02}}{\partial t}=\varepsilon_{2} \frac{\hat{o}^{2} y_{02}}{\partial x^{2}} ;|x|>a
$$

Since the configuration is symmetric with respect to the center of the river mouth, only a half of the problem domain will be treated. The boundary conditions are that no 
sediment transport is given through the center of the river (symmetry), and the beach must be continuous at all times between the two areas. Furthermore, the shoreline is unaffected by the sediment input as $x$ approaches infinity. The solution can be obtained as :

$$
y_{01}(x, t)=q_{R 0} t\left[1-2 \mathrm{j}^{2} \operatorname{erfc}\left(\frac{a-x}{2 \sqrt{\varepsilon_{2} t}}\right)-2 \mathrm{j}^{2} \operatorname{erfc}\left(\frac{a+x}{2 \sqrt{\varepsilon_{2} t}}\right)\right]
$$

for $t>0$ and $0 \leq|\boldsymbol{x}| \leq a$, and

$$
y_{02}(x, t)=2 q_{R 0} t\left[\mathrm{j}^{2} \operatorname{erfc}\left(\frac{x-a}{2 \sqrt{\varepsilon_{2} t}}\right)-\mathrm{j}^{2} \operatorname{erfc}\left(\frac{x+a}{2 \sqrt{\varepsilon_{2} t}}\right)\right]
$$

for $t>0$ and $|x|>a$.

The function jerfc, the integral of the complementary error function, was defined in Eq. (19) and the superscript 2 denotes a double integration. The $n$ exponent represents $n$ time integrations of the complementary error function. The following recurrence relation holds for $n>1$ :

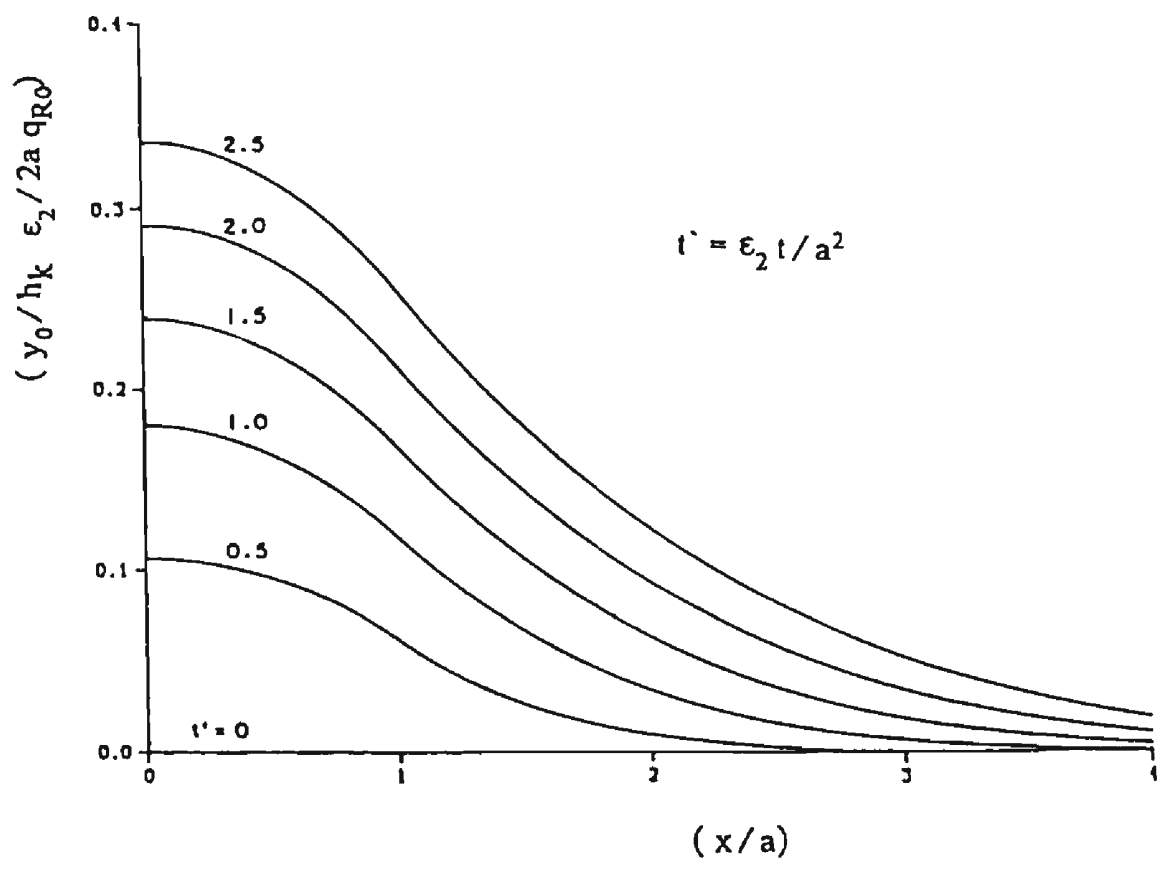

Fig. 4. Shoreline evolution in the formation of river delta of finite river width. 
$2 n \mathrm{j}^{n} \operatorname{erfc} \omega=\mathrm{j}^{n-2} \operatorname{erfc} \omega-2 \omega \mathrm{j}^{n-1} \operatorname{erfc} \omega$

The solution to Eqs. (25) and (26) is illustrated in Fig. 4, where the shoreline position is normalized by a half of the river width, $a$, and the following dimensionless quantity is introduced by Eq. (13) as;

$$
\frac{2 a q_{R 0}}{\varepsilon_{2}}=\frac{(1-\lambda) h_{k} Q_{R 0}}{\left[\partial Q_{x} / \partial \alpha_{b}\right]_{a_{b 0}}}
$$

which is interpreted as the ratio of the total sediment input from the river to the diffusivness of longshore wave power. In order to study the effect of the above dimensionless quantity on the plane shape of the river delta, the longshore distance from the center of the river mouth, denoted by $B$, where the shoreline position is a half of the shoreline position at the center of the river, is plotted in terms of the dimensionless quantity. The result is shown in Fig. 5, where $B$ is normalized by shoreline position $y_{0}$. From this figure it is obvious that ; 1) it general the distance $B$ decreases with an increase of the quantity which implies that as the delta becomes of river-dominated, the delta plane

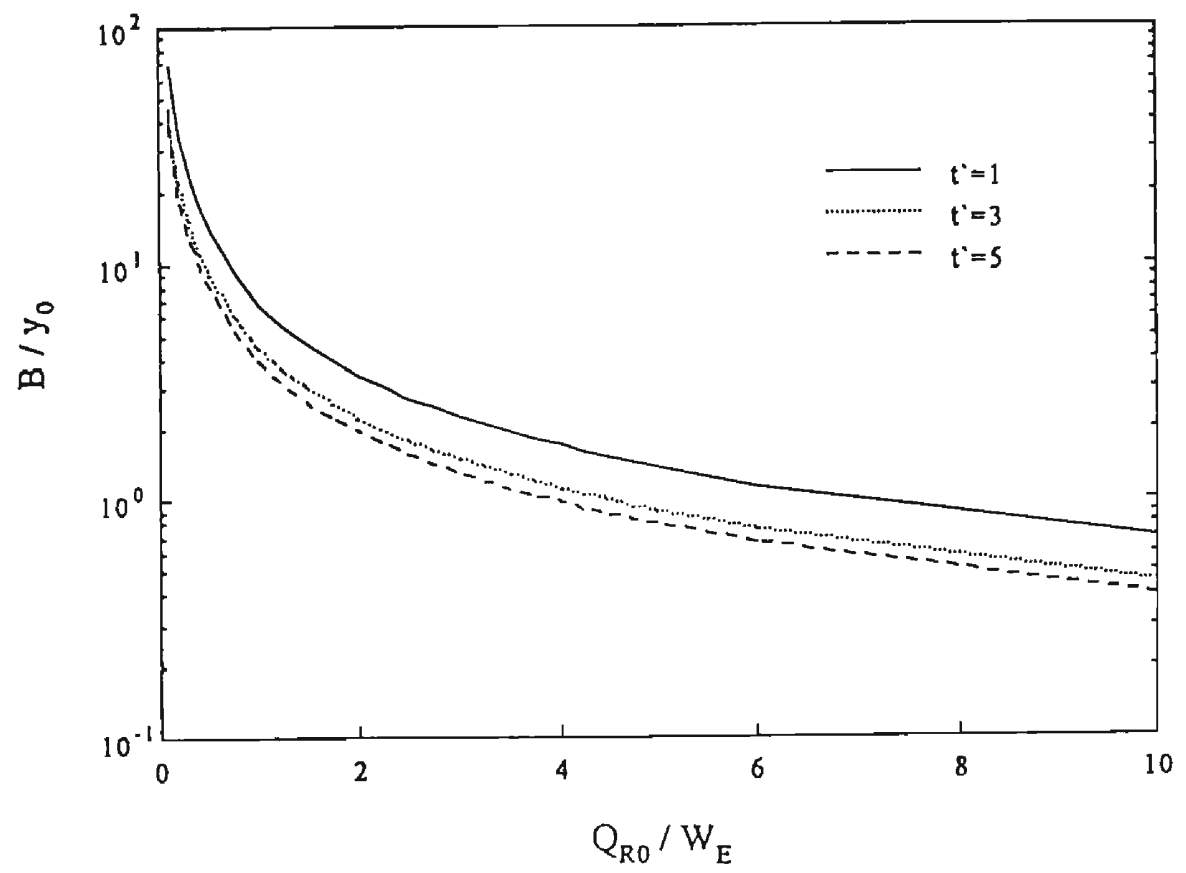

Fig. 5. Relationship between the longshore disatance $\mathbf{B}$ where the shoreline position is a half of maximum vlaue at the center of river mouth and the dimensionless quantity of sediment input and diffusivness of longshore wave power. 
shape becomes sharp with a large shoreline gradient near the river mouth, 2) on the contrary, as the quantity becomes smaller, the delta may be classified as wave-dominated type and the delta plane shape may be mild with a small shoreline gradient in the longshore direction, and 3 ) for a specific value of the quantity, the distance $B$ decreases with an increase of the dimensionless time $t$, which implies that the rate of deposited sediment around the river mouth increases with time.

2.3 Solution to shoreline change in the formation process of river delta by obliquely incident waves

In the previous solutions the waves always approach the coast river delta normally, and therefore, the configurations of river delta are symmetrical. When the waves approach the coast obliquely, it is expected that the shape of the delta will be asymmetric. Consider the case where a river mouth has a finite width, the continuity equation of sediment transport in the full form of Eq. (12) is applied as :

$$
\frac{\partial y_{01}}{\partial t}=-\varepsilon_{1} \frac{\partial y_{01}}{\partial x}+\varepsilon_{2} \frac{\partial^{2} y_{01}}{\partial x^{2}}+q_{R 0} ;-a \leq x \leq a
$$

and

$$
\frac{\partial y_{02}}{\partial t}=-\varepsilon_{1} \frac{\partial y_{02}}{\partial x}+\varepsilon_{2} \frac{\partial^{2} y_{02}}{\partial x^{2}} ;|x|>a
$$

with the initial condition,

$$
y_{01}(x, 0)=y_{02}(x, 0)=0
$$

and the boundary conditions,

$$
\begin{aligned}
& y_{01}=y_{02}, \frac{\partial y_{01}}{\partial x}=\frac{\partial y_{02}}{\partial x} \text { at }|x|=a \\
& y_{02}=0, \frac{\partial y_{02}}{\partial x}=0 \text { at }|x| \rightarrow \infty
\end{aligned}
$$

The problem consists of two coupled partial differential equations with appropriate initial and boundary conditions. By introducing the expression given by Eq. (14), Eqs. (29) and (30) are transformed to the diffusion type equations as :

$$
\frac{\partial z_{01}}{\partial t}=\varepsilon_{2} \frac{\partial^{2} z_{01}}{\partial x^{2}}+q_{R 0} \exp \left[-\frac{\varepsilon_{1}}{2 \varepsilon_{2}} x+\frac{\varepsilon_{1}^{2}}{4 \varepsilon_{2}} t\right] ;-a \leq x \leq a
$$

and 


$$
\frac{\partial z_{02}}{\partial t}=\varepsilon_{2} \frac{\partial^{2} z_{02}}{\partial x^{2}} ;|x|>a
$$

with the initial condition,

$$
z_{01}(x, 0)=z_{02}(x, 0)=0
$$

and the boundary conditions,

$$
z_{01}=z_{02}, \frac{\partial z_{01}}{\partial x}=\frac{\partial z_{02}}{\partial x} \text { at }|x|=a
$$

and

$$
z_{02}=0, \frac{\partial z_{02}}{\partial x}=0 \text { at }|x| \rightarrow \infty
$$

In order to solve the above equations with the appropriate initial and boundary conditions, the Laplace transformation is applied. It allows the target partial differential equation in the transformed plane to be used for solving one-dimensional problems in space. By using the Laplace transformation, the linear ordinary differential equations are obtained from Eqs. (34) and (35) respectively as :

$$
\frac{d^{2} W_{1}}{d x^{2}}-\frac{s}{\varepsilon_{2}} W_{1}=-\frac{q_{R 0}}{\varepsilon_{2}\left(s-\varepsilon_{1}^{2} / 4 \varepsilon_{2}\right)^{2}} \exp \left[-\frac{\varepsilon_{1}}{2 \varepsilon_{2}} x\right] ;-a \leq x \leq a
$$

and

$$
\frac{d^{2} W_{2}}{d x^{2}}-\frac{s}{\varepsilon_{2}} W_{2}=0 ; \quad|x|>a
$$

where the function $W$ denotes the transformed function of $z_{0}$, and the subscripts 1,2 refer to the two applied areas. The function $W$ is defined by :

$$
W=L\left\{z_{0}\right\}=\int_{0}^{\infty} z_{0}(x, t) e^{-s t} d t
$$

The boundary conditions of Eqs. (37) and (38) are transformed respectively to;

$$
W_{1}=W_{2}, \frac{\partial W_{1}}{\partial x}=\frac{\partial W_{2}}{\partial x} \text { at }|x|=a
$$

and 


$$
\begin{aligned}
& W_{2}=0, \frac{\partial W_{2}}{\partial x}=0 \text { at }|x| \rightarrow \infty \\
& W_{1}=C_{1} e^{x R}+C_{2} e^{-x R}+\frac{q_{R 0}}{\left(s-\varepsilon_{1}^{2} / 4 \varepsilon_{2}\right)} \exp \left[-\frac{\varepsilon_{1}}{2 \varepsilon_{2}} x\right] ;-a \leq x \leq a
\end{aligned}
$$

and

$$
\boldsymbol{W}_{2}=D_{1} e^{x R}+D_{2} e^{-x R} ;|x|>a
$$

where

$$
R^{2}=s / \varepsilon_{2}
$$

The coefficients $C_{1}, C_{2}, D_{1}$ and $D_{2}$ must be determined from the boundary conditions, Eqs. (42) and (43), and they are, in general, functions of the parameter $s$. To obtain a solution in the time domain, Eqs (44) and (45) can be inversely transformed to obtain

$$
z_{01}(x, t)=F_{1}(x, t) \exp \left[-\left(\frac{\varepsilon_{1}}{\varepsilon_{2}}\right) t\right] ; t \geq 0 \text { and } 0 \leq|x| \leq a
$$

and

$$
z_{02}(x, t)=F_{2}(x, t) \exp \left[-\left(\frac{\varepsilon_{1}}{\varepsilon_{2}}\right)|x|+\left(\frac{\varepsilon_{1}^{2}}{4 \varepsilon_{2}}\right) t\right] ; t \geq 0 \text { and }|x| \geq a
$$

where

$$
\begin{aligned}
& \frac{F_{1}(x, t)}{q_{R 0} t}=1-2 \mathrm{j}^{2} \operatorname{erfc}\left(\frac{a-x}{2 \sqrt{\varepsilon_{2} t}} \mid\right)-2 \mathrm{j}^{2} \operatorname{erfc}\left(\frac{a+x}{2 \sqrt{\varepsilon_{2} t}}\right) \\
& \quad+\left(\frac{2 \varepsilon_{1} a}{\varepsilon_{2}}\right) \mathrm{j}^{3} \operatorname{erfc}\left(\frac{x-a}{2 \sqrt{\varepsilon_{2} t}}\right)-\left(\frac{2 \varepsilon_{1} a}{\varepsilon_{2}}\right) \mathrm{j}^{3} \operatorname{erfc}\left(\frac{x+a}{2 \sqrt{\varepsilon_{2} t}}\right) \exp \left(-\frac{\varepsilon_{1}}{\varepsilon_{2}} a\right)
\end{aligned}
$$

and

$$
\begin{aligned}
& \frac{F_{2}(x, t)}{q_{R 0} t}=\mathrm{j}^{2} \operatorname{erfc}\left(\frac{x-a}{2 \sqrt{\varepsilon_{2} t}}\right)-\mathrm{j}^{2} \operatorname{erfc}\left(\frac{x+a}{2 \sqrt{\varepsilon_{2} t}}\right) \\
& \quad+\left(\frac{2 \varepsilon_{1} a}{\varepsilon_{2}}\right) \mathrm{j}^{3} \operatorname{erfc}\left(\frac{x-a}{2 \sqrt{\varepsilon_{2} t}}\right)-\left(\frac{2 \varepsilon_{1} a}{\varepsilon_{2}}\right) \mathrm{j}^{3} \operatorname{erfc}\left(\frac{x+a}{2 \sqrt{\varepsilon_{2} t}}\right) \exp \left(-\frac{\varepsilon_{1}}{\varepsilon_{2}} a\right)
\end{aligned}
$$

Substituting of Eq. (14) into Eqs. (47) and (48), the solution to Eqs. (29) and (30) is 


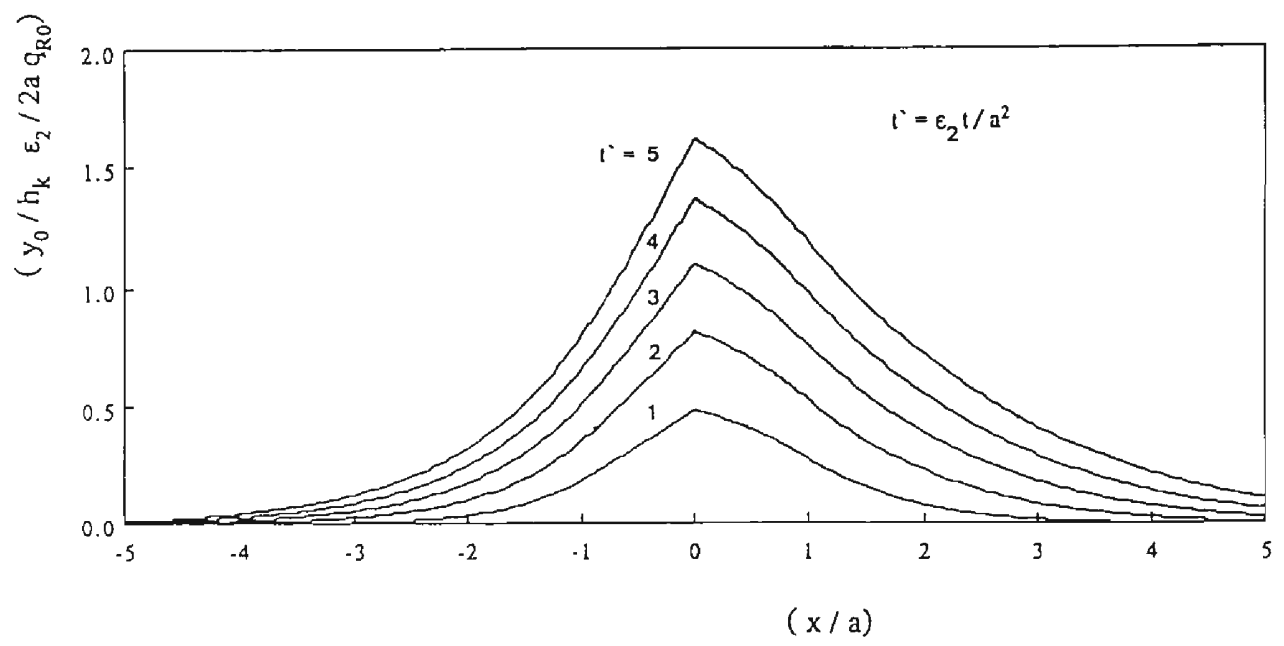

Fig. 6. Shoreline evolution in the formation of river delta by obliquely incident waves.

finally obtained as :

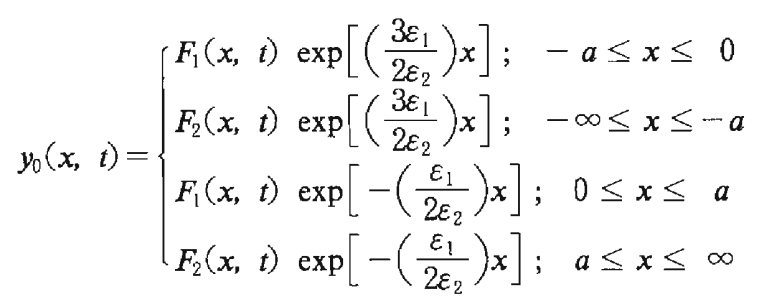

The time evolution of river delta by Eq. (51) is illustrated in Fig. 6, where the dimensionless quantity describing the shoreline position is defined by :

$$
y_{0}^{\prime}=\frac{y_{0}}{a} \frac{\varepsilon_{2}}{2 a q_{R 0}}
$$

It is well understood in this figure that the asymmetric plane shape of the delta is clearly formed by obliquely incident waves. The dimensionless quantity describing the effect of beach slope change and oblique wave incident on the configuration of river delta is defined according to $\varepsilon_{1} a / \varepsilon_{2}$. Fig. 7 demonstrates the effect of the quantity $\varepsilon_{1} a / \varepsilon_{2}$ on the configuration of river delta. It is clearly seen that the configuration of river delta becomes asymmetric when $\varepsilon_{1} a / \varepsilon_{2}$ is greater than zero. The degree of asymmetrical configuration of the river delta becomes highly significant as the quantity $\varepsilon_{1} a / \varepsilon_{2}$ increases, which implies that as the incident wave angle increases, the asymmetrical configuration of the river delta becomes significantly remarkable. It is also obvious from the figure that the shoreline gradient, $\left|\partial y_{0} / \partial x\right|$, becomes larger with an increase of $\varepsilon_{1} a / \varepsilon_{2}$ which means 


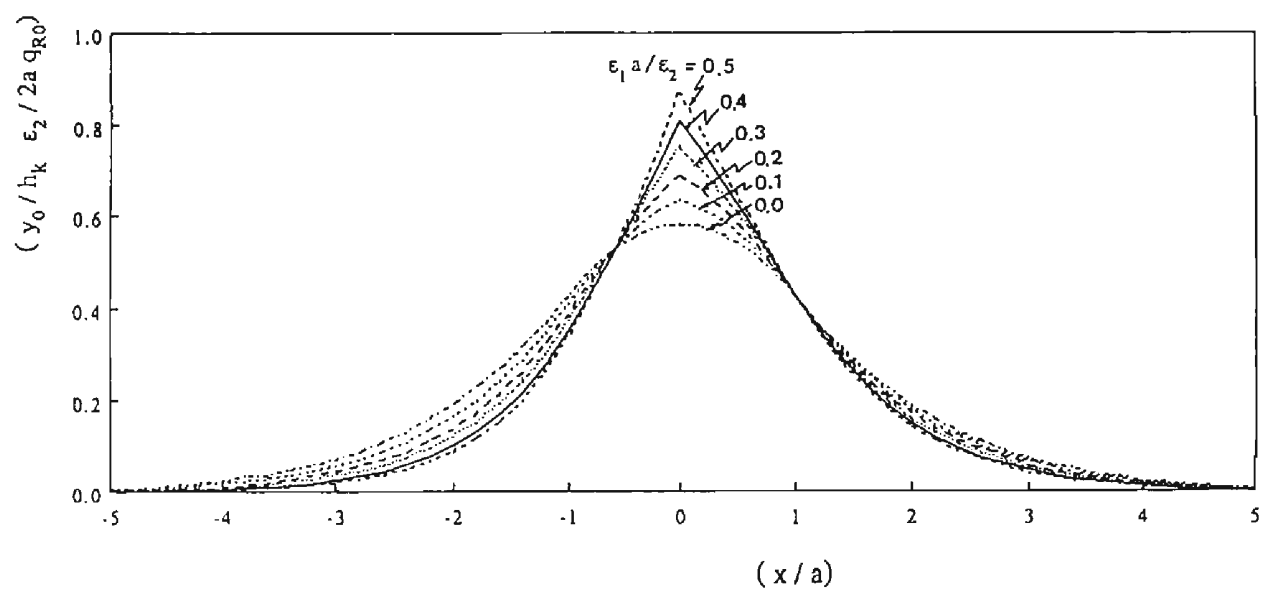

Fig. 7. Influence of the dimensionless quantity $\varepsilon_{1} a / \varepsilon_{2}$ on the configuration of river delta at $t=2$.

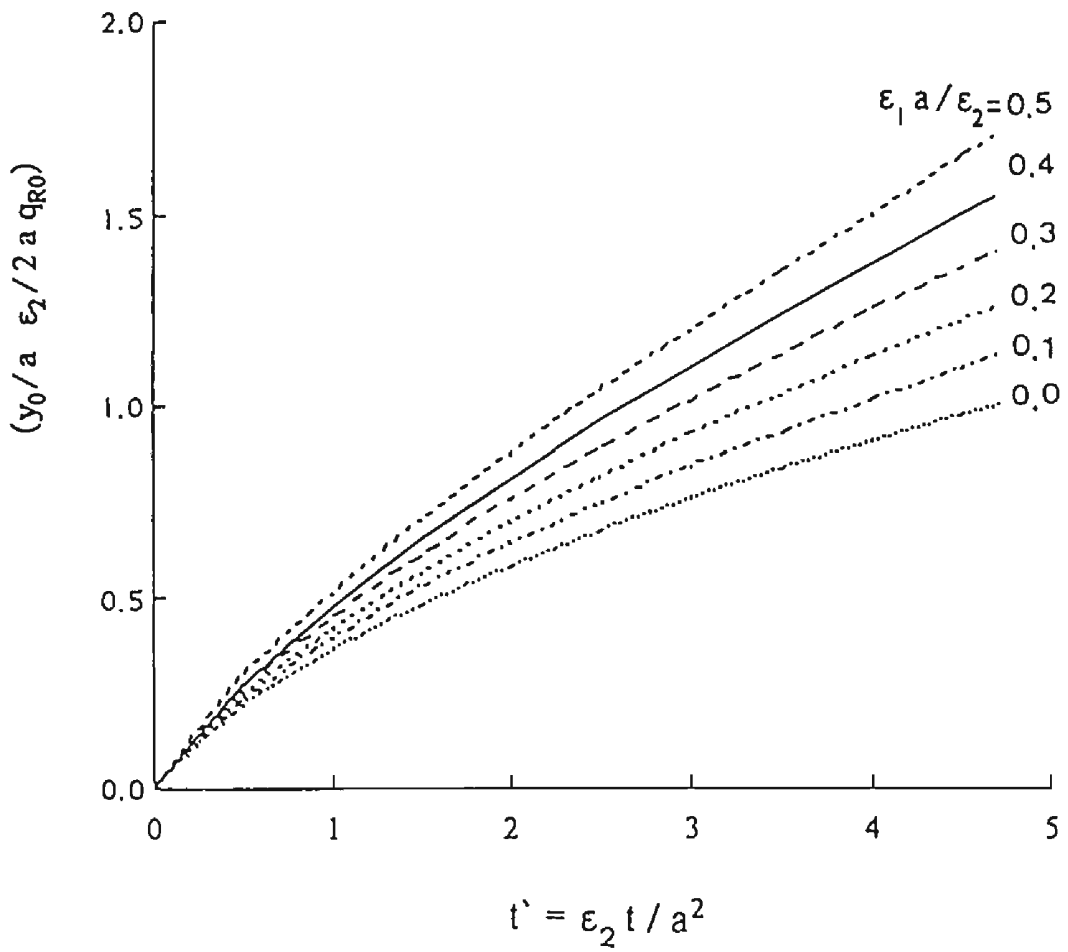

Fig. 8. Influence of the dimensionless quantity $\varepsilon_{1} a / \varepsilon_{2}$ on the time variation of shoreline change at the center of river mouth. 
that increasing the rate of beach slope change along the river delta causes the shape of river delta to be distinctly formed.

The effect of the quantity $\varepsilon_{1} a / \varepsilon_{2}$ on the growth of delta at the center of the river mouth is shown in Fig. 8. It is obvious from the figure that; 1) the shoreline position at the center of the river mouth increases with an increase of $\varepsilon_{1} a / \varepsilon_{2}$, and 2) as $\varepsilon_{1} a / \varepsilon_{2}$ increases, the rate of delta growth at the center of the river mouth decreases.

\subsection{Solution to shoreline changes in the reduction process of river delta}

The reduction process of river delta occurs due to a decrease or lack of sediment input from the river, in which the rate of sediment removal by the longshore currents is larger than the rate of sediment input from the river. Generally, the equations describing the shoreline changes in the reduction process of river delta are the same as used in the formation process of river delta except that the river sediment input is no longer considered. Therefore, the linear partial differential equation describing the shoreline change is given as :

$$
\frac{\partial y_{0}}{\partial t}+\varepsilon_{1} \frac{\partial y_{0}}{\partial x}-\varepsilon_{2} \frac{\partial^{2} y_{0}}{\partial x^{2}}=0
$$

By specifying the initial and boundary conditions in the areas which represent conditions prevailing in a specific shoreline evolution, the corresponding solutions are directly applicable. The associated initial and boundary conditions are given respectively as:

$$
\left.\begin{array}{lll}
y_{0}=g(x) & \text { at } & t=0 \\
y_{0}=\frac{\partial y_{0}}{\partial x}=0 & \text { at } & x \rightarrow \pm \infty
\end{array}\right)
$$

By substituting the expression given in Eq. (14) into Eq. (53), Eq. (53) can be transformed to a diffusion type eqaution

$$
\frac{\partial z_{0}}{\partial t}=\varepsilon_{2} \frac{\partial^{2} z_{0}}{\partial x^{2}}
$$

with the initial and boundary conditions,

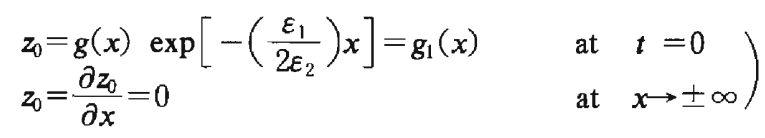

Thus the general solution of shoreline changes can be expressed as :

$$
y_{0}(x, t)=z_{0}(x, t) \exp \left[\left(\frac{\varepsilon_{1}}{2 \varepsilon_{2}}\right) x-\left(\frac{\varepsilon_{1}^{2}}{4 \varepsilon_{2}}\right) t\right] ; \quad t \geq 0 \text { and }-\infty \leq x \leq \infty
$$


where

$$
z_{0}(x, t)=\frac{1}{2 \sqrt{\pi \varepsilon_{2} t}} \int_{-\infty}^{\infty} g_{1}\left(x^{\prime}\right) \exp \left[-\frac{\left(x-x^{\prime}\right)^{2}}{4 \varepsilon_{2} t}\right] d x^{\prime}
$$

The evaluation of the integration presented in Eq. (57) is influenced by the choice of the initial shoreline position. In the following cases of river delta reduction, the initial shoreline position will be determined with the aid of the formation process of river delta.

\section{(1) Reduction of river delta of infinite length by normally incident waves}

Since the river delta has an infinite length and waves are assumed to approach the shoreline normally, the coefficient $\varepsilon_{1}$ becomes very small and can be neglected. Also, the reduction process will take symmetrically with respect to the center of the river delta. Thus, the initial shoreline position in this case can be given from the formation process of river delta of infinite length as :

$$
y_{0}(x, 0)=h_{k} q_{R} \sqrt{\frac{t_{0}}{\varepsilon_{2}}} \mathrm{j}^{2} \operatorname{erfc}\left(\frac{x}{2 \sqrt{\varepsilon_{2} t_{0}}}\right)=g_{1}(x)
$$

where the river sediment discharge $q_{R}$ which is completely trapped and has been used to form the river delta during a previous time $t_{0}$, and both $q_{R}$ and $t_{0}$ are now treated as constants. Substituting the initial condition presented by Eq. (59) into Eqs. (57) and (58), the solution of shoreline changes is reduced to

$$
y_{0}(x, t)=\frac{h_{k} q_{R}}{2 \sqrt{\pi} \varepsilon_{2}} \sqrt{\frac{t_{0}}{t}} \int_{-\infty}^{\infty} \mathrm{j}^{2} \operatorname{erfc}\left(\frac{x^{\prime}}{2 \sqrt{\varepsilon_{2} t_{0}}}\right) \exp \left[-\frac{\left(x-x^{\prime}\right)^{2}}{4 \varepsilon_{2} t}\right] d x^{\prime}
$$

In Fig. 9, the solution to Eq. (60) is illustrated. The shoreline position is normalized by the limiting water depth of littoral drift, $h_{k^{\prime}}$ and the ratio $h_{k} g_{k} / \varepsilon_{2}$, while the longshore distance is normalized by $h_{k}$. In this figure the reduction process of river delta is taking place symmetrically with respect to the center of the river. The reduction rate of river delta at the center of the river diminishes with time, while the shoreline at the longshore ends of the river delta is replenished with time. The final stage for the configuration of the delta will be demonstrated as a straight beach. This phenomenon is clearly seen in Fig. 10 in a dimensionless expression, where the time variation of shoreline along the river delta is illustrated.

\section{(2) Reduction of river delta of finite river mouth by normally incident waves}

In the case of river mouth with a finite width of $2 a$ and normally incident waves, the initial shoreline positions can be given by the plane shape of river delta of a finite river mouth as : 


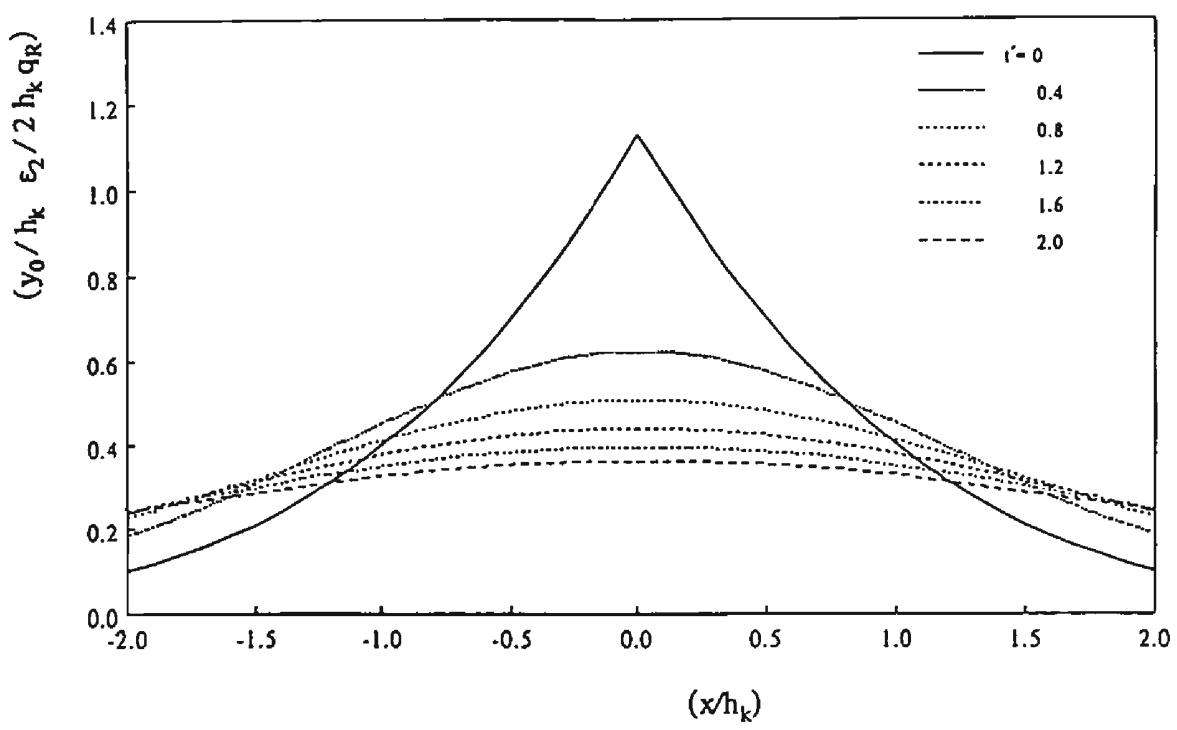

Fig. 9. Time variation of shoreline change in the reduction process of river delta of infinte river width.

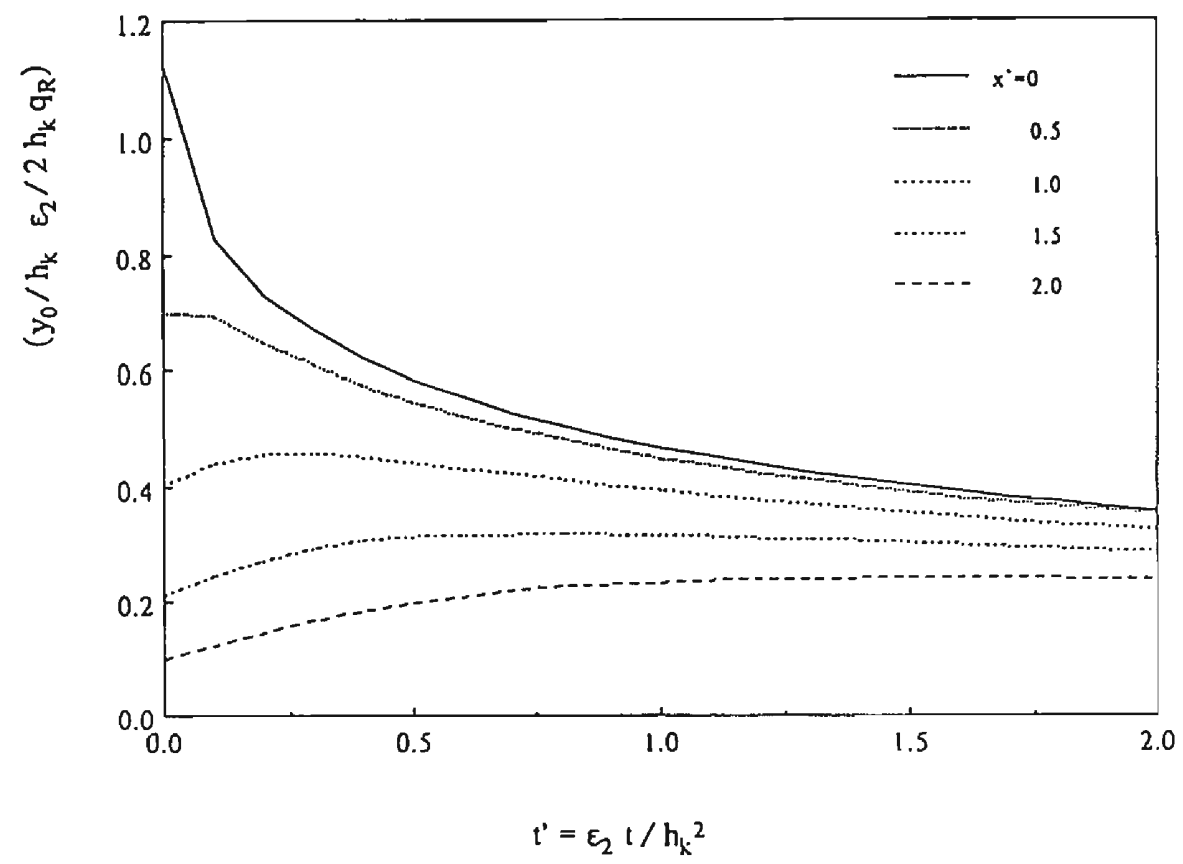

Fig. 10. Time variation of shoreline change at several positions along the river delta in the reduction process of river delta of infinite river width. 


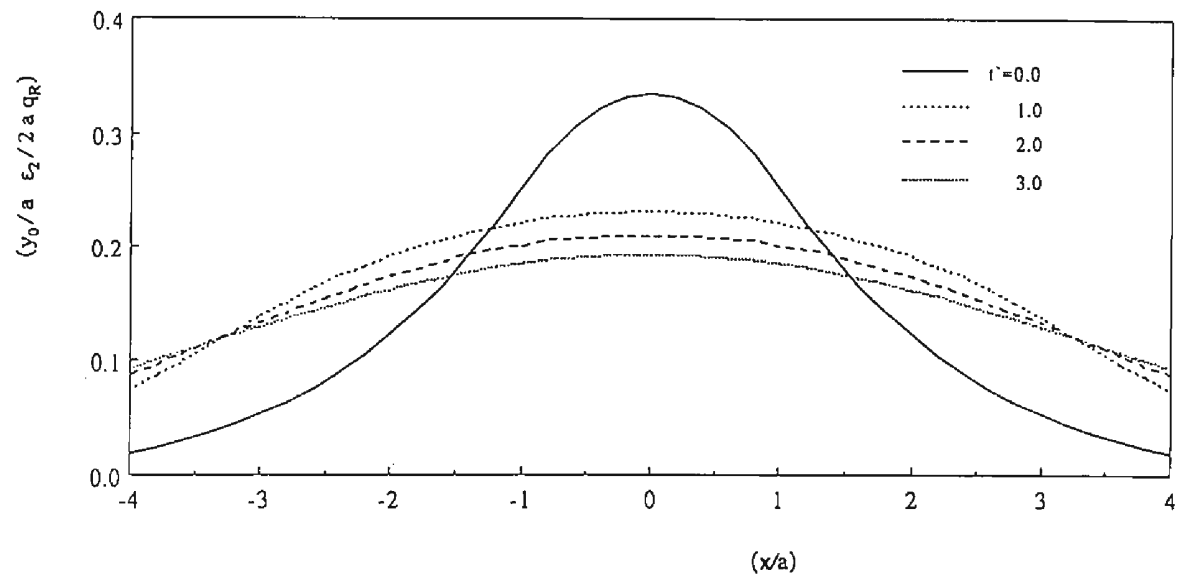

Fig. 11. Time variation of shoreline change in the reduction process of river delta of finite width.

$$
\begin{aligned}
y_{01}(x, 0) & =q_{R} t_{0}\left[1-2 \mathrm{j}^{2} \operatorname{erfc}\left(\frac{a-x}{2 \sqrt{\varepsilon_{2} t_{0}}}\right)-2 \mathrm{j}^{2} \operatorname{erfc}\left(\frac{a+x}{2 \sqrt{\varepsilon_{2} t_{0}}}\right)\right] \\
& =q_{R} t_{0} g_{1}(x) ; 0 \leq|\boldsymbol{x}| \leq a
\end{aligned}
$$

and

$$
\begin{aligned}
y_{02}(x, 0) & =q_{R} t_{0}\left[2 \mathrm{j}^{2} \operatorname{erfc}\left(\frac{x-a}{2 \sqrt{\varepsilon_{2} t_{0}}}\right)-\mathrm{j}^{2} \operatorname{erfc}\left(\frac{x+a}{2 \sqrt{\varepsilon_{2} t_{0}}}\right)\right] \\
& =q_{R} t_{0} g_{2}(x) ; \quad|x| \geq a
\end{aligned}
$$

Substituting the above initial conditions into Eq. (57), the solution to shoreline changes is finally given as :

$$
\begin{gathered}
y_{0}(x, t)=\frac{q_{R} t_{0}}{\sqrt{\pi \varepsilon_{2} t}}\left[\frac{1}{2} \int_{-a}^{a} g_{1}\left(x^{\prime}\right) \exp \left\{-\frac{\left(x-x^{\prime}\right)^{2}}{4 \varepsilon_{2} t}\right\} d x^{\prime}+\int_{a}^{\infty} g_{2}\left(x^{\prime}\right) \exp \left\{-\frac{\left(x-x^{\prime}\right)^{2}}{4 \varepsilon_{2} t}\right\} d x^{\prime}\right. \\
\left.\quad+\int_{-\infty}^{-a} g_{2}\left(x^{\prime}\right) \exp \left\{-\frac{\left(x-x^{\prime}\right)^{2}}{4 \varepsilon_{2} t}\right\} d x^{\prime}\right] ; t \geq 0 \text { and }-\infty \leq x \leq \infty
\end{gathered}
$$

The solution to Eq. (63) is illustrated in Fig. 11, where the shoreline position is normalized by a half of the river width, $a$, and the dimensionless quantity $2 a q_{R} / \varepsilon_{2}$. As in the previous case, the reduction process of river delta takes place symmetrically with respect to the center of the river. The reduction rate of river delta at the center of the river diminishes with time, while the shoreline at the alongshore ends of the river delta is 
replenishes with time. The final stage for the configuration of the delta becomes a straight beach.

(3) Asmmetric change of shoreline position of river delta

In the previous cases the waves are assumed to approach the shoreline normally, therefore the reduction process takes place symmetrically with respect to the center of the river delta. When the waves approach the coast of river delta obliquely, the shoreline change is expected to occur asymmetrically. Consider the case where the river mouth has a finite width, the initial shoreline position can be obtained by the same way as in the formation process, as :

$$
y_{0}(x, t)=q_{R} t_{0}\left\{\begin{array}{l}
F_{1}(x) \exp \left[-\left(\frac{\varepsilon_{1}}{2 \varepsilon_{2}}\right) x\right] ; \quad a \leq x \leq \infty \\
F_{2}(x) \exp \left[-\left(\frac{\varepsilon_{1}}{2 \varepsilon_{2}}\right) x\right] ; \quad 0 \leq x \leq a \\
F_{1}(x) \exp \left[\left(\frac{3 \varepsilon_{1}}{2 \varepsilon_{2}}\right) x\right] ; \quad-a \leq x \leq 0 \\
F_{2}(x) \exp \left[\left(\frac{3 \varepsilon_{1}}{2 \varepsilon_{2}}\right) x\right] ; \quad-\infty \leq x \leq-a
\end{array}\right.
$$

where

$$
\begin{gathered}
F_{1}(x)=1-2 \mathrm{j}^{2} \operatorname{erfc}\left(\frac{a-x}{2 \sqrt{\varepsilon_{2} t_{0}}}\right)-2 \mathrm{j}^{2} \operatorname{erfc}\left(\frac{a+x}{2 \sqrt{\varepsilon_{2} t_{0}}}\right)+2\left(\frac{\varepsilon_{1} a}{\varepsilon_{2}}\right) \mathrm{j}^{3} \operatorname{erfc}\left(\frac{x-a}{2 \sqrt{\varepsilon_{2} t_{0}}}\right) \\
-2\left(\frac{\varepsilon_{1} a}{\varepsilon_{2}} \mid\right) \mathrm{j}^{3} \operatorname{erfc}\left(\frac{x+a}{2 \sqrt{\varepsilon_{2} t_{0}}}\right) \exp \left(-\frac{\varepsilon_{1} a}{\varepsilon_{2}}\right) ; 0 \leq|x| \leq a
\end{gathered}
$$

By use of Eq. (14), the initial condition, Eq. (64) is expressed as :

$$
z_{0}(x)=q_{R} t_{0}\left\{\begin{array}{lr}
F_{1}(x) \exp \left[-\left(\frac{\varepsilon_{1}}{\varepsilon_{2}}\right) x\right] ; & a \leq x \leq \infty \\
F_{2}(x) \exp \left[-\left(\frac{\varepsilon_{1}}{\varepsilon_{2}}\right) x\right] ; & 0 \leq x \leq a \\
F_{2}(x) \exp \left[\left(\frac{\varepsilon_{1}}{\varepsilon_{2}}\right) x\right] ; & -a \leq x \leq 0 \\
F_{1}(x) \exp \left[\left(\frac{\varepsilon_{1}}{\varepsilon_{2}}\right) x\right] ; & -\infty \leq x \leq-a
\end{array}\right.
$$

Thus, the solution of shoreline change is finally obtained as :

$$
y_{0}(x, t)=z_{0}(x, t) \exp \left[\left(\frac{\varepsilon_{1}}{2 \varepsilon_{2}}\right) x-\left(\frac{\varepsilon_{1}^{2}}{4 \varepsilon_{2}}\right) t\right] ; t \geq 0 \text { and }-\infty \leq x \leq \infty
$$

where 


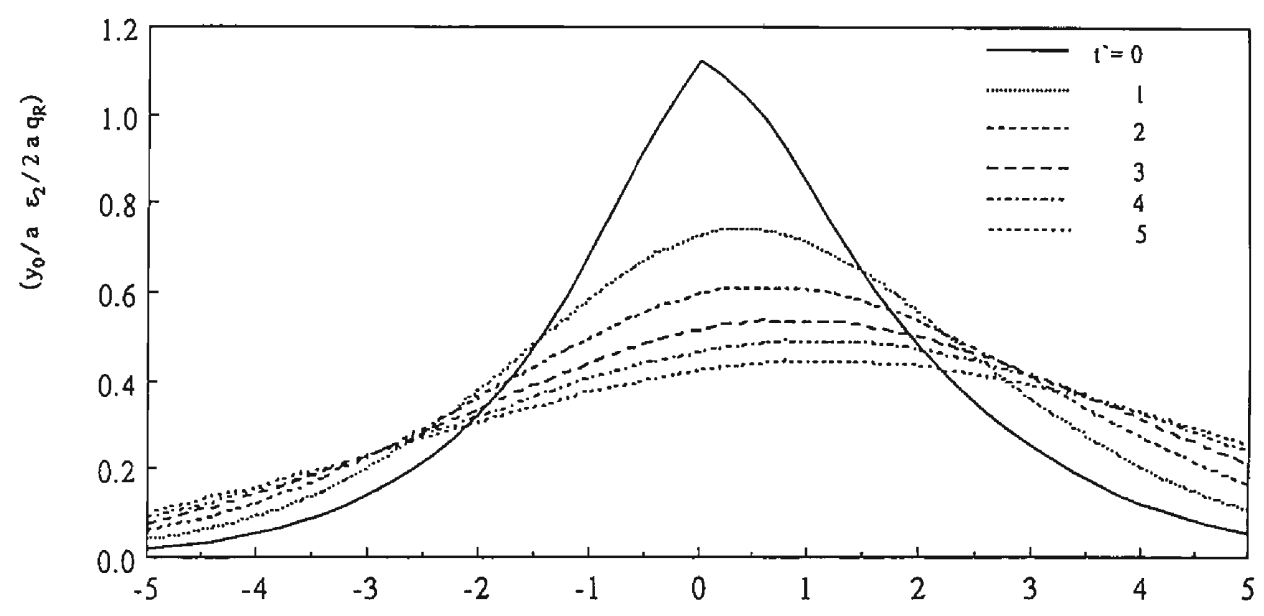

$(x / a)$

Fig. 12. Time variation in shoreline change in the reduction process of asymmetric river delta by obliquely incident waves in the case where $\varepsilon_{1} a / \varepsilon_{2}=0.2$.

$$
\begin{aligned}
& z_{0}(x, t)= \frac{q_{R} t_{0}}{2 \sqrt{\pi \varepsilon_{2}}}\left[\int_{a}^{\infty} F_{1}(x) \exp \left[-\frac{\left(x-x^{\prime}\right)^{2}}{4 \varepsilon_{2} t}+\left(\frac{\varepsilon_{1}}{\varepsilon_{2}}\right) x^{\prime}\right] d x^{\prime}+\int_{0}^{a} F_{2}\left(x^{\prime}\right)\right. \\
& \exp \left[-\frac{\left(x-x^{\prime}\right)^{2}}{4 \varepsilon_{2} t}-\left(\frac{\varepsilon_{1}}{\varepsilon_{2}}\right) x^{\prime}\right] d x^{\prime}+\int_{-a}^{0} F_{2}\left(x^{\prime}\right) \exp \left[-\frac{\left(x-x^{\prime}\right)^{2}}{4 \varepsilon_{2} t}+\left(\frac{\varepsilon_{1}}{\varepsilon_{2}}\right) x^{\prime}\right] d x^{\prime} \\
& \\
&\left.+\int_{-\infty}^{-a} F_{1}\left(x^{\prime}\right) \exp \left[-\frac{\left(x-x^{\prime}\right)^{2}}{4 \varepsilon_{2} t}+\left(\frac{\varepsilon_{1}}{\varepsilon_{2}}\right) x^{\prime}\right] d x^{\prime}\right]
\end{aligned}
$$

In Fig. 12, the solution to Eq. (68) is illustrated. The asymmetric shape of the delta is clearly seen in this figure. Since the waves approach the shoreline obliquely, the longshore sediment transport is predominant. Consequently, most of the sediment moves in the predominant direction of littoral drift. As a result, the reduction rate of the shoreline on the upstream coast side is greater than the reduction rate of the shoreline in the downcoast. Also, the river mouth changes in shape in the predominant direction of littoral drift, as clearly seen in the figure. The final stage for the configuration of the delta may become an inclined straight beach which the waves tend to approach normally.

\section{Experiments on the Formation and Reduction Processes of River Deltas}

\section{1 Experiments on the Formation Process of River Deltas}

The formation and reduction processes of river deltas of wave- and river-dominated type are controlled by the interaction between two main forces; sediment input from the river and wave power. If the rate of sediment input from the river is greater than the 
rate of sediment removal as longshore sediment transport, the formation process of river delta will take place. On the contrary, if the rate of sediment input from the river is less than the rate of sediment removal, beach erosion along the delta, which is a reduction process, of river delta will take place.

The time scale for beach change of river deltas is generally in the order of 100 years, therefore the seasonal changes of beach profile and shoreline positions during severe storms will not be considered when studying the formation process of river deltas. In fact, the beach profile often returns to its pre-storm shape in a short time, typically within several weeks. In contrast, imbalances in the longshore sediment transport rate cause a more gradual and permanent change in the beach plane form.

The main objectives of this experimental study are to demonstrate the formation process of river deltas, to consider the physical process of changing beach profile along the shoreline of river delta, to verify the relationship between shoreline position and cross -sectional area of beach profile, and finally to study the effect of oblique wave incidence on the symmetrical configuration of the river delta and the formation process of asymmetrical river deltas.

\section{(1) Methods of modeling of river sediment input}

In hydraulic experiments, modeling of river sediment input is not an easy task. Before experiments on river delta formation can be carried out, alternative methods for modeling a river sediment input to the beach should be examined, showing the advantage and disadvantage of every method. Finally, the most appropriate method must be determined. Mainly, there are three methods to model river sediment input. One deals with supplying water and sediment by using a channel, the other two methods deal with supplying a dry sediment as a point source or a line source. The details of each method are discussed as follows :

a) Method of supplying water and sediment In trying to copy nature, where the actual river flows, carrying sediment, the most appropriate method is construct a channel in which the water is pumped with sediment and discharged into the wave basin. To have a clear understanding of this method, many factors must be considered, with discussing the effect of each factor on the formation process of river deltas and on the experimental conditions. These factors are summarized as :

1) Effect of stream velocity: In the case of high stream velocity, the sediment is discharged and deposited out of the surf zone where the effect of longshore current is minor, resulting in formation of curved propagating backward in time to connect the initial shoreline. The configuration of this river delta is mainly due to river action, while the incoming waves will cause a shifting of the deformed shape to the right or to the left depending on the direction of the incident waves. Accordingly, it is implied that due to the strong water discharge, the river delta shape becomes the so-called fan-shaped river delta, and therefore, the scale and position of the alluvial fan are very unstable and severely change with time. On the contrary in the case of low velocity the sediment is deposited near the upper most end of a channel, resulting in closing the channel, so that no more sediment is available to form a river delta. Thus, there exists a critical range 
of stream velocity which is able to carry sediment and deposit it within the surf zone.

2) Effect of additional water from river: It has been clearly shown that the velocity of the discharged water affects the formation process of river delta, and must be taken into consideration when this method is considered. Another factor that may not be ignored is additional amounts of water entering the wave basin which strongly affects the characteristics of the incoming waves via changing the water level in the wave basin. The solution to this problem is quite easy ; the same amount of water must be discharged in order to keep a constant water level in the basin.

3) Characteristics of sediment particles and rate of river sediment input: A sediment particle under the action of flowing water takes either a state of repose or movement in accordance with the degree of fluid force to the resistant force of the particle. In a moving state, which is classified as either suspension or bed load such as rolling, sliding and saltation, the sediment particle movement is determined by the critical shear velocity $u_{*}$, which corresponds to the threshold condition of sediment movement. Generally, $u_{*_{c}}$ can be predicted by Shields diagram. The sediment particle diameter may be nearly proportional to the critical shear velocity and falling velocity. The particles whose falling velocities are smaller than the critical shear velocities will be kept in suspension; the other particles whose falling velocities are larger than the critical shear velocities will be deposited onto the channel bed.

The rate of sediment input can be controlled by using a sediment feeding system with a motor controlling device. If the rate of sediment input is larger than the rate of the sediment removal by wave action, the sediment will deposit at the river mouth, causing a stream velocity decrease, resulting in a deposition of sediment on the channel bed behind the river mouth. On the contrary, if the rate of sediment input is smaller than the rate of sediment removal, no delta is formed and all sediment particles are carried away.

b) Methods of supplying dry sediment Since the sediment input from the river is responsible for building up a delta, in order to avoid the effect of water discharge on the process of formation of river delta, we will consider the supplying of dry sediment as sediment input from a river. Although it is easy to model a river sediment input by supplying dry sediment, rather than by using water and sediment, some problems still remain. Generally, two methods can be considered to model river sedment input using dry sediment as; the point source and line source method. In both methods, the motor controlled sediment feeding is used to supply sediment at a constant rate. The main difference between the two methods arises in the distribution of the sediment over the deltaic area as :

1) First method (Supplying sediment as a point source): The sediment is supplied at a single point, which may cause concern with the assumption that the river mouth width is very small compared with the finite length of the shoreline. Now, some questions arise as follows; 1) where is the best position for the point source?, 2) is it better to fix the position of the point source or to move it as the shoreline propagates?, and finally 3) if it is moving, what should be the rate of that movement?

For the first question, three possible positions may exist for the point source, they 
are: 1) at the shoreline, 2) within the surf zone and 3) outside the surf zone. The choice of point source to be located at the shoreline tends to accumulate the sedimnt resulting in the formation of a small hill. This is because at the shoreline the longshore current velocity too weak to carry the sediment away. From the fact that the longshore currents are stronger inside the surf zone, the point source must be located within the surf zone. If the point stource is chosen to be outside the surf zone, the longshore currents are unable to carry the sediment. As a result, a longshore bar will be formed. Generally speaking, it is therefore suggested that the position of the point source be at the location of the maximum value of longshore sediment transport, which is just shoreward of the breaker line.

Generally, when a river delta is formed and propagates seaward, the breaker line moves seaward too in a similar way. It is therefore suggested to make the position of the point source move seaward at the same rate as the propagation of the shoreline of river delta and to keep the position of the point source near the location of maximum longshore sediment transport being located just shoreward of the breaker line.

2) Second method (Supplying sediment as a line source): From the point of view of the cross-shore distribution of longshore sediment transport, which takes a maximum value shoreward of the breaker line, a line source method is proposed. The line source consists of holes of different diameters, in which the sediment is discharged over the surf zone in the distribution similar to that of longshore sediment transport. It is a preferable method where the distribution of longshore sediment transport is required. Additionally, around the river mouth the longshore sediment transport becomes nonuniform. Thus, it is believed that the point source method is easier to apply than the line source method, and it is quite satisfactory for the observation of formation processes of a river delta when the results of experiment are to be compared with theoretical ones.

From the above description of the different methods of modeling river sediment input to the model beach, the following points must be noted :

(1) The river sediment is only responsible for building up a delta, therefore the method of supplying water with sediment will be excluded, and the methods of supplying dry sediment are only applied for this purpose of the experiment.

(2) The assumption that the river mouth width is very small compared with the infinite length of the shoreline gives the point source method as an advanced step over the line source method.

(3) When the line source method is used, the rate of river sediment input will be related to the rate of longshore sediment transport and its seaward distribution.

From the above points, we decided to use the point source method for modeling the sediment input from a river to the beach. Some preliminary experiments were carried out to verify the applicability of the point source method for modeling the river sediment input.

\section{(2) Experimental procedure}

The experiments were performed in the fan-shaped wave basin (semicircular part: $r$ $=17.5 \mathrm{~m}$ and rectangular part $: 35 \times 10 \mathrm{~m}$ ) of Ujigawa Hydraulics Laboratory, Disaster 


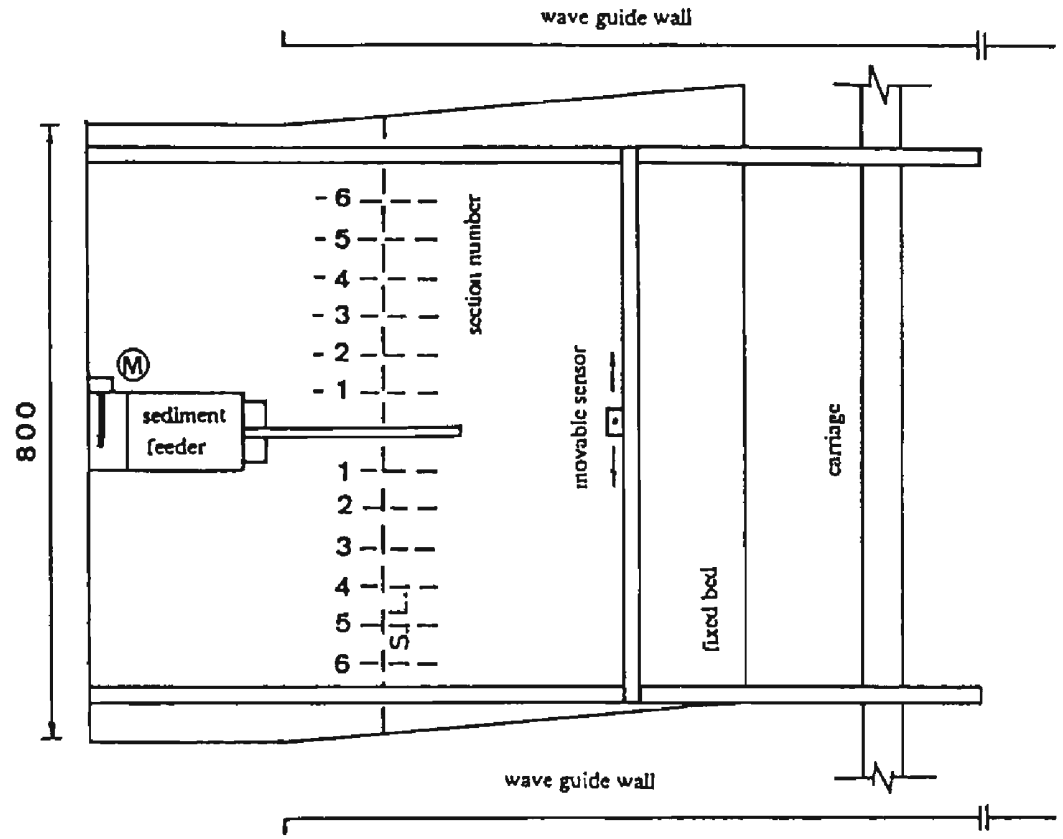

(a) Plane view.

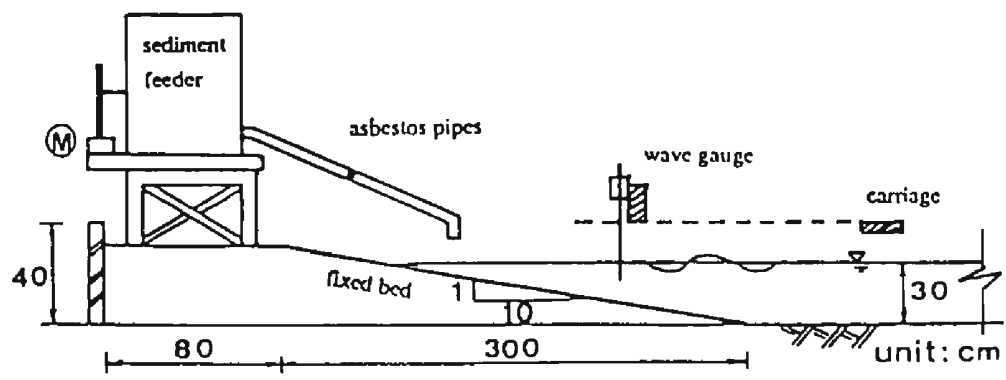

(b) Side view.

Fig. 13. Schematic diagram of experimental arrangement of formation and reduction processes of river deltas.

Prevention Research Institute, Kyoto University. A smooth concrete beach was constructed with a slope of $1 / 10$. The beach was roughened by bonding light weight aggregate, the same material as that used for modeling river sediment input, onto the smooth concrete. The wave guide walls, which are composed of smooth steel plates, were installed normal to the wave generator. The smooth steel plates had been chosen so that the amplitude of refracted waves was expected to be minimal as shown in Fig. 13.

On the land side, a sediment feeder machine with a variable speed motor was set 
about $1.0 \mathrm{~m}$ from the initial shoreline shown in the figure. The light weight aggregate material was chosen to model the river sediment input. This material is very sensitive to wave action and has a low friction coefficient. The variable speed motor was used to supply sediment at a constant rate into the model beach. Two smooth asbestos pipes of different diameters were connected to the sediment feeder machine at the output opening in order to carry the sediment to the desired position of the point source. The small diameter pipe smoothly slid inside the large diameter one allowing no sediment particles to fall between them. Thus, this system gave a free and accurate adjustment for the position of the point source. Measurements of sediment input rate were performed 1) at the beginning of the experiments, and 2) at every $10 \mathrm{~min}$ during the experiments. Then the rate of sediment input was calculated as the average value of the measured dediment rates.

Measurements of shoreline positions were made at $10 \mathrm{~min}$ intervals along the delta at 13 stations ( $50 \mathrm{~cm}$ interval distance) as shown in Fig. 13. At the end of each experiment, beach profiles as well as shoreline changes were measured every $10 \mathrm{~cm}$ along the delta. The measurements of beach profiles were made by an acoustic sensor mounted on a carriage, and controlled by a personal computer. The measured profiles were transformed to digital data and recorded using a low frequency digitizer. The formation process of river delta was observed by taking photographs every 10 minutes with a $35 \mathrm{~mm}$ automatic camera. The camera was mounted at a height of $5-7 \mathrm{~m}$ above the water surface. The camera suspension system allows the camera to be accurately positioned and leveled.

On the wave basin side, measurements of wave heights in the constant depth part were made using capacitance type wave gauges. While on the sloping part, the measurements were made using a wave gauge mounted on a carriage controlled by a personal computer. The angles of incoming wave incidence were measured in the constant depth part by measuring the angles of inclination of the wave generator to the beach. Snell's law and linear wave theory were used to estimate the angles of wave incidence at the breaker line. The longshore currents were visually observed by using colored paper tracers.

\section{(3) Experimental results}

Six experiments were performed (see Table 1), with a still water depth of $30 \mathrm{~cm}$, a wave height of $2.0 \mathrm{~cm}$ and a wave period of $0.8 \mathrm{sec}$. The incoming waves were normally incident during the experiment series $\mathbf{A}$ and $\mathbf{B}$, while they were obliquely incident during experiments $\mathrm{C}-1$ and $\mathrm{D}-1$, at $7.5^{\circ}$ and $15^{\circ}$, respectively. The experimental results are as follows :

a) General description of river delta formation process Once the sediment feeder machine supplied sediment to the model beach, the sediment spread along the beach by the effect of the longshore current. Also, a small delta gradially formed on the fixed bed and propagated seaward at nearly the same rate as the front line of the delta, which meant that the beach profile was moving in parallel to itself. The position of point source is moved seaward just behind the breaker point, the supplied sediment redistri- 
buting along the river delta by the effect of longshore currents.

It was observed that sediment was first deposited around the river mouth then moved a considerable distance from the river mouth until it deposited at the initial shoreline, forming a new shoreline. During that time more sediment deposited at the river mouth and once again moved a considerable distance from the river mouth till it deposited at the initial shoreline forming another shoreline, and so on, until finally, a series of layers appeared each layer representing a complete cycle of shoreline evolution in the formation process of river delta.

b) Characteristics of growth of river delta Fig. 14 shows the accretional processes of shoreline in the formation of a river delta in experiments series $\mathrm{A}$ and $\mathrm{B}$, respectively. Since the rate of sediment input was kept constant and relatively small, $Q_{R 0}=7.0 \mathrm{~cm}^{3} / \mathrm{sec}$, during the experiments of $\mathrm{A}-1$ and $\mathrm{A}-2$, the measured shoreline positions shown in Fig. 14(a) at $t=50 \mathrm{~min}$ and $80 \mathrm{~min}$, respectively, are parallel to each other. Also, the con-

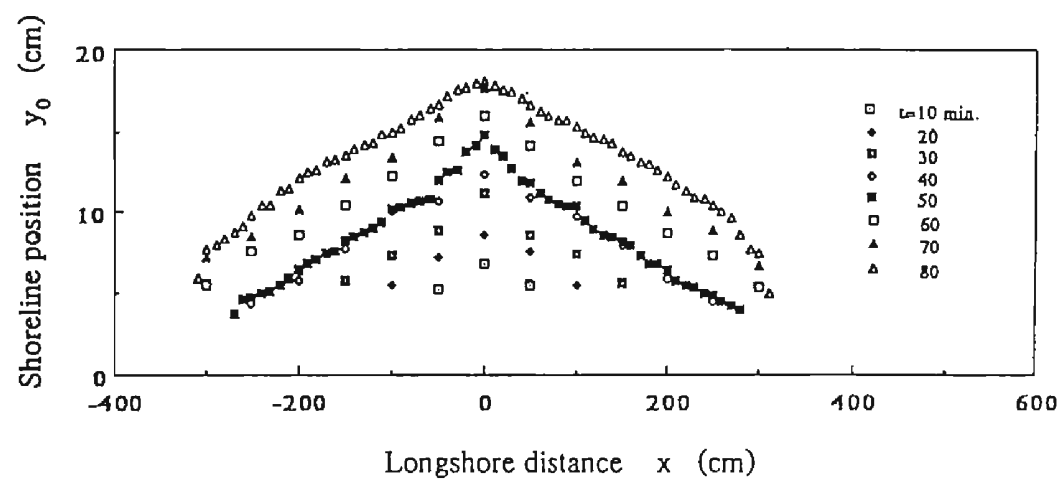

(a) In the case of Series $A$

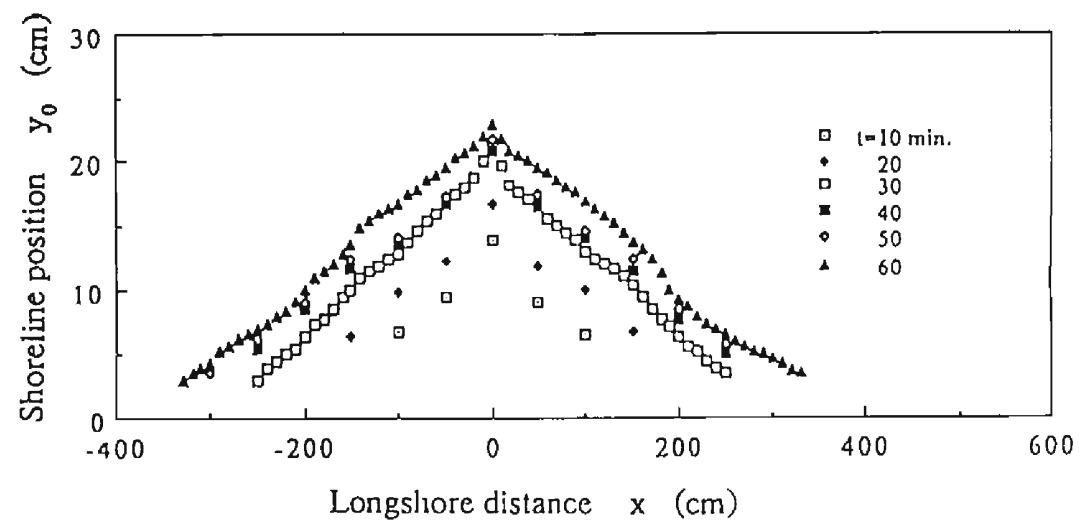

(b) In the case of Series $B$

Fig. 14. Accretional process of shoreline in the formation of river delta. 
figuration of the shoreline of river delta in these experiments is nearly symmetric with respect to the center of the river delta. In Series $B$, the rate of sediment input was relatively high, $Q_{R 0}=15.0 \mathrm{~cm}^{3} / \mathrm{sec}$ in Run B-1 and reduced by half in Run B-2. Therefore, the measured shoreline positions shown in Fig. 14(b) at $t=30 \mathrm{~min}$ and $60 \mathrm{~min}$ are not perfectly parallel. Moreover, much more sediment was deposited around the point source than near the end of the delta. As a result, the configuration of the shoreline of river delta becomes sharply curved.

c) River delta configurations in the cases of normal and oblique wave incidence It is expected under a condition of normal wave incidence that the configuration of river delta

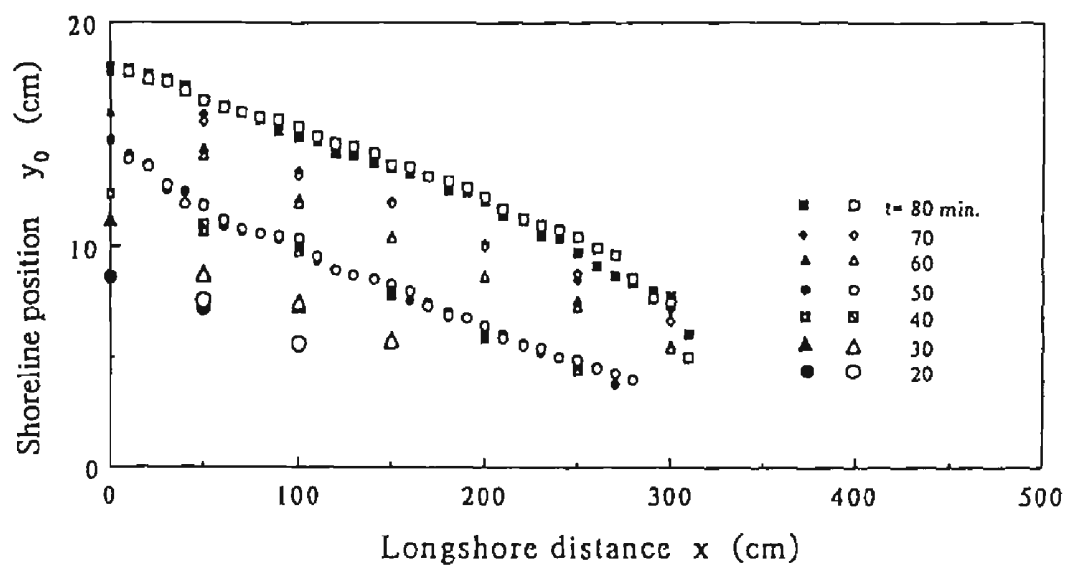

(a) In the case of Series $\mathrm{A}$

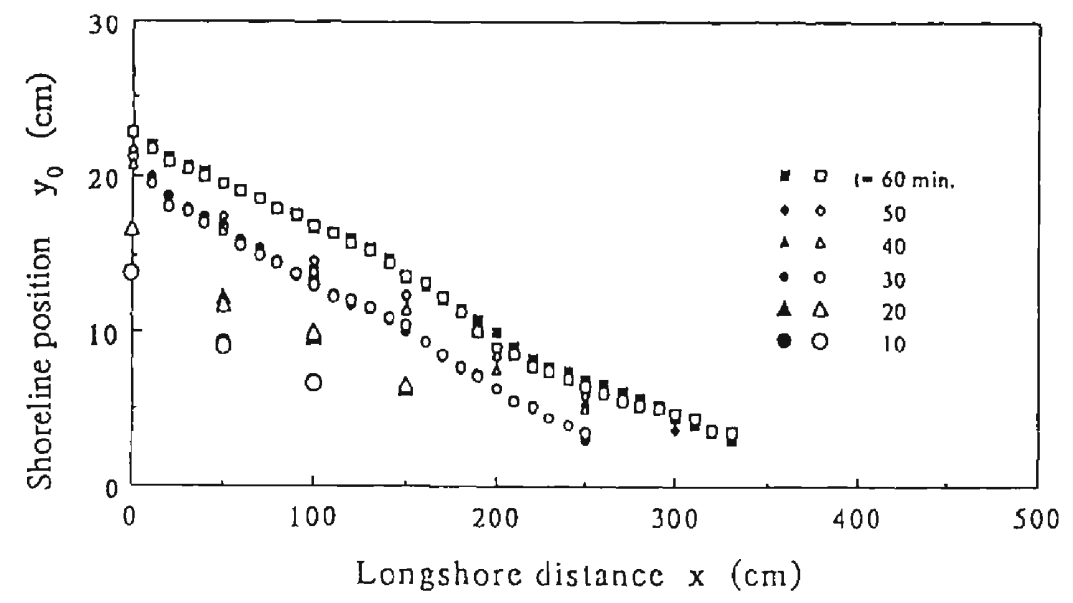

(b) In the case of Series B

Fig. 15. Symmetricalness of river delta configuration in the case of normal wave incidence. 


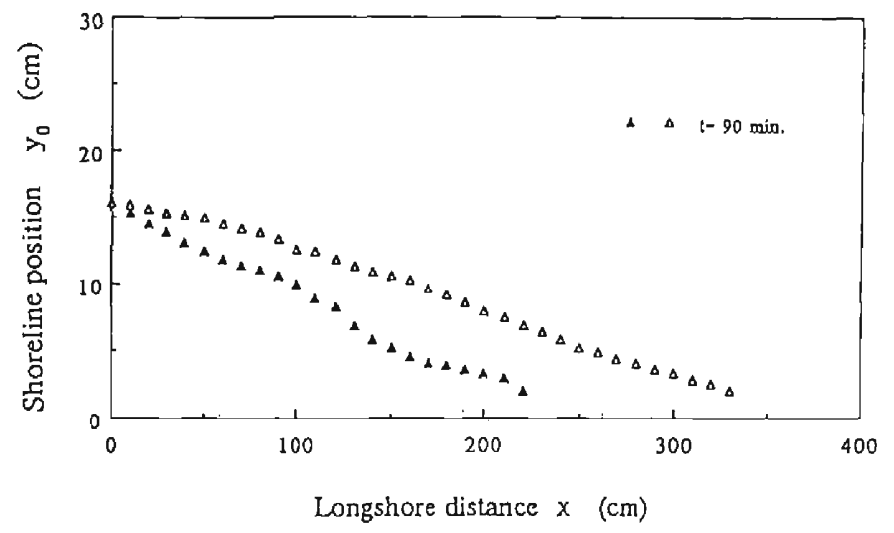

(a) In the case of Run C-1

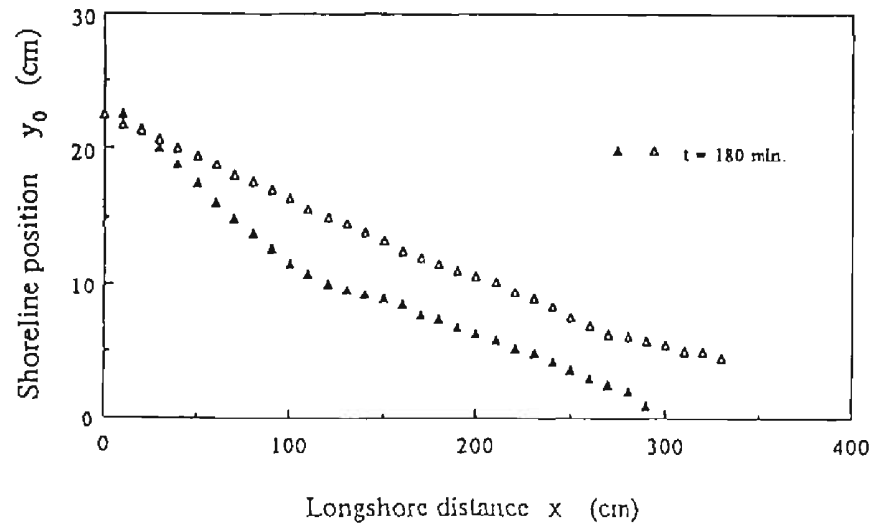

(b) In the case of Run D-1

Fig. 16. Asymmetricalness of river delta configuration in the case of oblique wase incidence.

is symmetric. To verify this phenomenon in the laboratory, measured data of shoreline positions on the left and right sides of the delta are plotted on one side as shown in Fig. 15(a) for Run A-1 and Run A-2, and in Fig. 15(b) for Run B-1 and Run B-2, respectively. The closed symbols represent the measured data on the left side, whereas the measured data on the right side are represented by the open symbols. The symmetrical configuration of the river delta is satisfied in these figures.

In the case of oblique wave incidence, on the contrary, an asymmetrical shape of river delta is expected. The sides of river delta are respectively named upcoast and downcoast side, with respect to the wave direction. The upcoast side is defined as the side of river delta which is directly affected by wavse, while the downcoast side is defined as the side where the wave effect is indirect. Fig. 16 illustrates the measured 
data of shoreline positions in Run C-1 and Run D-1 where the angles of wave incident are $7.5^{\circ}$ and $15.0^{\circ}$, respectively. The closed symbols represent the measured data at the upcoast side whereas the measured data at the downcoast side are represented by the open symbols. It is clear that asymmetrical river deltas are formed in the case of oblique wave incidence. In general, oblique waves generate strong longshore currents. Consequently, most of the river sediment is transported in the predominant direction of littoral drift and deposited on the downcoast side. Therefore, the growth rate of the shoreline on the downcoast side is faster than that on the upcoast side.

d) Effect of longshore currents on the configuration of river delta When waves approach a straight beach at an oblique angle, the longshore wave power generates longshore currents along the beach. Therefore, in the case of normal wave incidence, theoretically, no longshore currents exist. When we consider a river discharging on a straight beach where the incoming waves are normally incident, initially, no longshore currents exist, but as the river delta forms causing variations in space and time of the shoreline orientation, nearshore currents such as longshore currents are established, too due to changes in the nearshore bathymetry. Furthermore, due to wave refraction by the nearshore bathymetry, even when the offshore wave climate is constant, the longshore current is generated and varies along the river delta. This longshore current carries the river sediment and redistributes it along the delta to form a new river delta shoreline which is gently curved in the case of wave-dominated delta type, and sharply curved in the case of river-dominated delta type. This new river delta shoreline affects in tum the nearshore bathymetry to generate another longshore current. A more realistic description of a real beach requires the incorporation of the wave-bottom interaction whereby the configuration of river delta is affected by the nearshore bathymetry. Because waves are coming normally to the shoreline, the configuration of delta may be symmetric with respect to the river mouth and the generated longshore currents may take place along both sides of the river delta.

Considering the case of obliquely incident waves with a river discharging on a straight beach, initially, a uniform longshore current is generated by waves along the beach. Once the river delta starts to be formed, an additional current is generated, which then flows along the river delta in both directions. Mathematically, this additional current generated by the effect of river delta formation reduces the longshore current generated by waves on the upcoast side and increases it on the downcoast side. As a result, on the upcoast side of river delta a weak longshore current results, while on the downcoast side a strong longshore current exists. Consequently, most of the river sediment is transported in the direction of the strong current and deposited on the downcoast side. At the upcoast side of river delta, a small amount of river sediment input forms a delta and reduces the longshore current until reaching a shape in dynamic equilibrium where the incoming waves approach the shoreline on that side at nearly a right angle. Thus, an asymmetrical shape of the river delta is formed.

e) Time variation of shoreline positions Fig. 17 shows the time variation of shoreline in Series A and B. Since the configuration of the river delta is symmetric with respect to the river mouth, only a half of the plane shape is considered. In the figure, seven ide- 


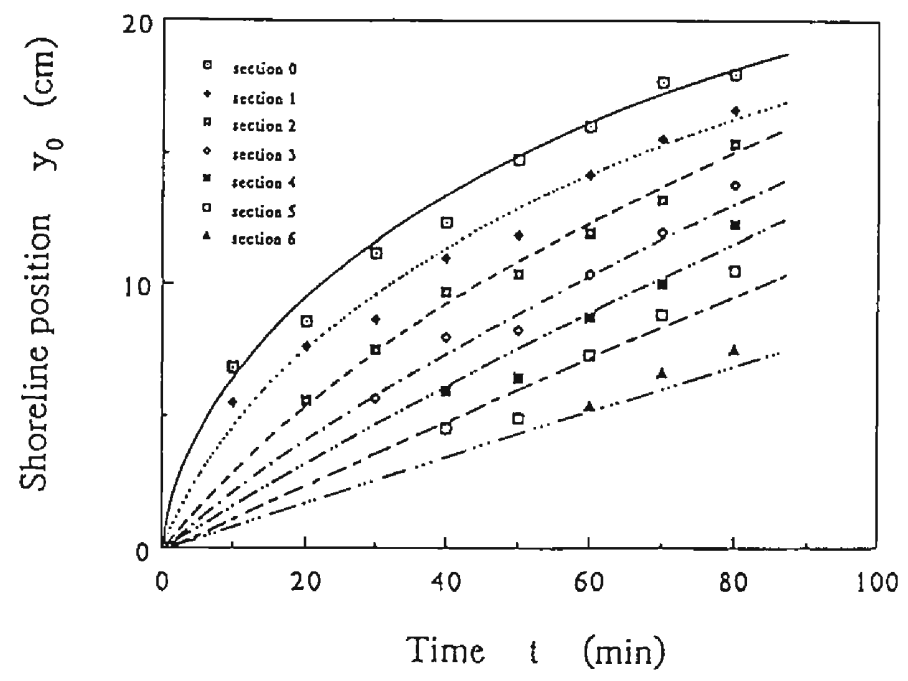

(a) In the case of Series $\mathrm{A}$

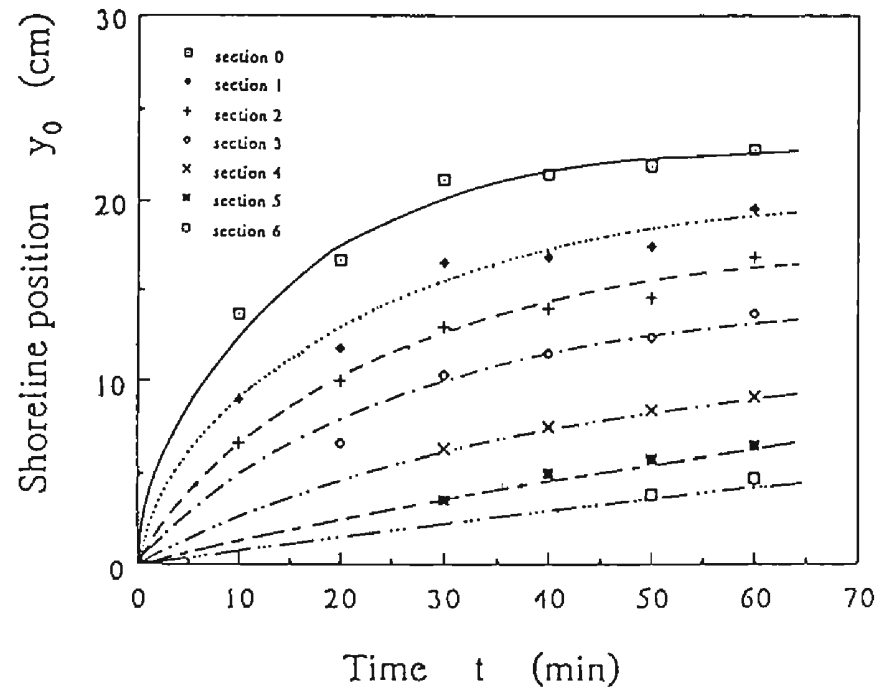

(b) In the case of Series $B$

Fig. 17. Time variation of shoreline change in the formation process of river delta.

alized sections were selected as shown in Fig. 13, to illustrate the time variation of shoreline positions. It is noted from the figure that, in general, the shoreline position, $y_{0}$, increases with increasing time, $t$. For a short time $t$, the shoreline position at the center of the river mouth, represented by section 0 , increases rapidly, while the shoreline at the end of the delta, represented by section 6 , increases more slowly. 
f) Variation of beach profile and beach slope along a delta coast The beach profiles were measured along the river delta at every $10 \mathrm{~cm}$ by using acoustic sensors mounted on a carriage controlled by a personal computer. The beach profiles measured along the river delta for experimental Run $\mathrm{A}-2$, at $t=80 \mathrm{~min}$, for the selected sections are illustrated in Fig. 18(a). It is seen from the figure that the beach profiles are convex in shape, probably due to quick deposition of sediment, and that a little longshore variation of beach profiles were observed. This phenomenon occurs when the longshore wave power is relatively stronger than the rate of river sediment input, or in other words, when the delta is categorized as a wave dominated type, as in Series $\mathbf{A}$, and also when the configuration of the shoreline of the river delta is gently curved. In this case, as shown in Fig. 19(a), a little longshore variation of beach slope at the shoreline are observed to show that nearly constant beach profiles may be assumed in the numerical simulation of shoreline change. At the end of the river delta, the roughness of the fixed bed caused a sudden change in the beach profile, which should be considered as the experimental limit.

In Series B, the rate of river sediment input was relatively predominant, or the delta can be categorized as a river-dominated type. The beach profiles measured for Run B-1 at $t=30 \mathrm{~min}$, vary along the river delta as shown in Fig. 18(b). It is obvious that beach profiles change along the river delta. Fig. 19(b) demonstrates the variation of beach slope at the shoreline along the river delta for Run B-1, represented by a white symbol, and Run B-2, represented by a black symbol, respectively. It is obvious from this figure that; 1) in Run B-1, the beach slopes around the river mouth were steeper than those at the longshore ends of the river delta, where the configuration of river delta is also sharply curved, and 2) when the rate of river sediment input was reduced by half in Run B-2, the configuration of the shoreline of the river delta changed, becoming more gently curved, and therefore, variation of beach profiles along the river delta lessened.

From Figs. 18 and 19, it can be inferred that 1) in the case of a wave-dominated delta, the variations of the beach profile along the river delta are very small with a mild beach slope, with the configuration of the shoreline of the gently curving river delta, and 2) in the case of a river-dominated delta, the configuration of the shoreline of the delta is sharply curved, and the beach profile varies along the delta with a steeper beach slope at the river mouth and milder one near the longshore end sides of the river delta.

g) Relationship between cross-sectional area and shoreline position Based on the assumption of one-line theory, that the beach profile moves in parallel to itself in the shoreline change, the cross-sectional area of the beach profile is proportional to the shoreline change. The relationship is linear, in which the gradient of the straight line is equal to the limiting depth for littoral drift, $h_{k}$ which is written as :

$$
A=h_{k} y_{0}
$$

To illustrate this relationship, the measured data of shoreline positions are plotted against the equivalent measured data of cross-sectional area of beach profiles. The data are shown in Fig. 20(a), (b) and (c) for Series A, B, C, and D, respectively. The ex- 


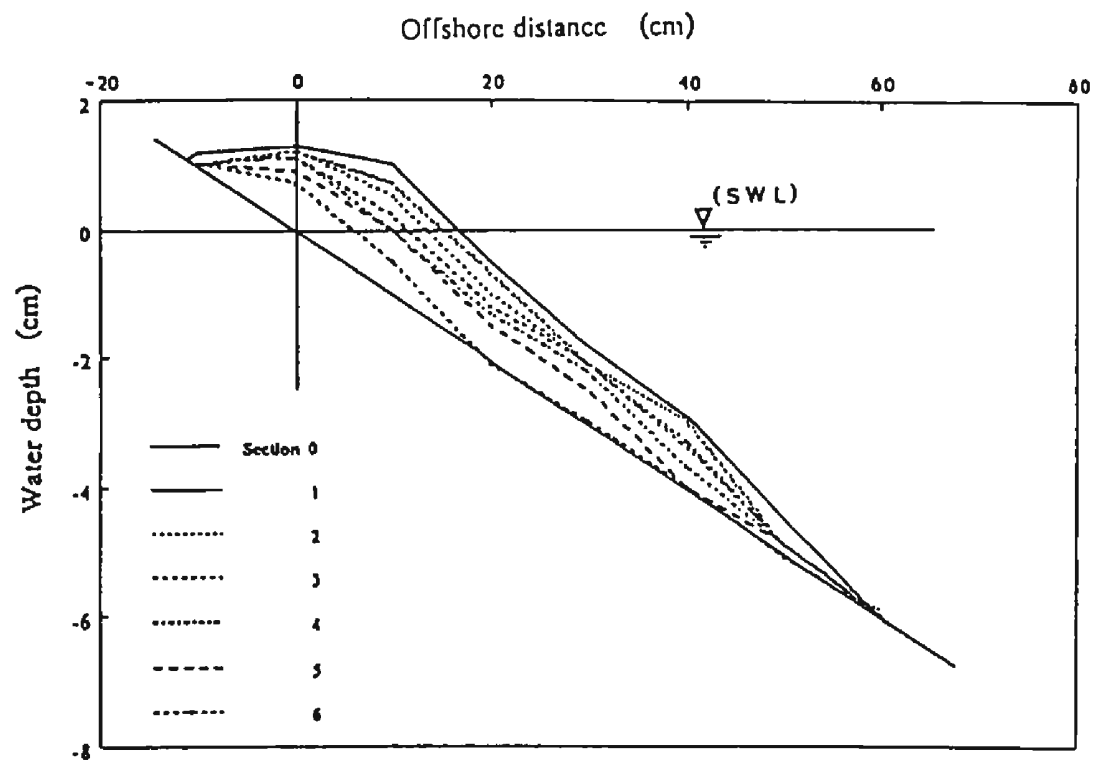

(a) In the case of Run A-2

Orfshore dis!ance $(\mathrm{cm})$

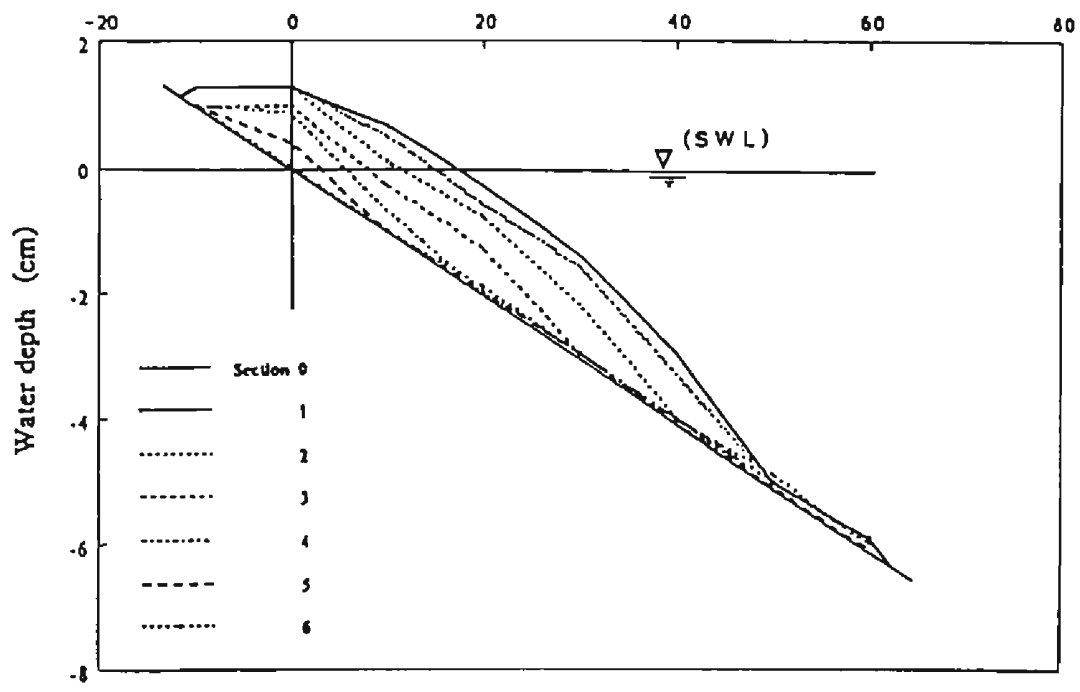

(b) In the case of Run B-1

Fig. 18. Variation of beach profiles formed along the shoreline of river delta formed.

perimental values of relation between the cross-sectional area, $A$, of beach profile and the shoreline position, $y_{0}$, from the datum line are scattered, but the general trend is linear. This scattering behavior is believed to be correlated to the nonuniformity of longshore 


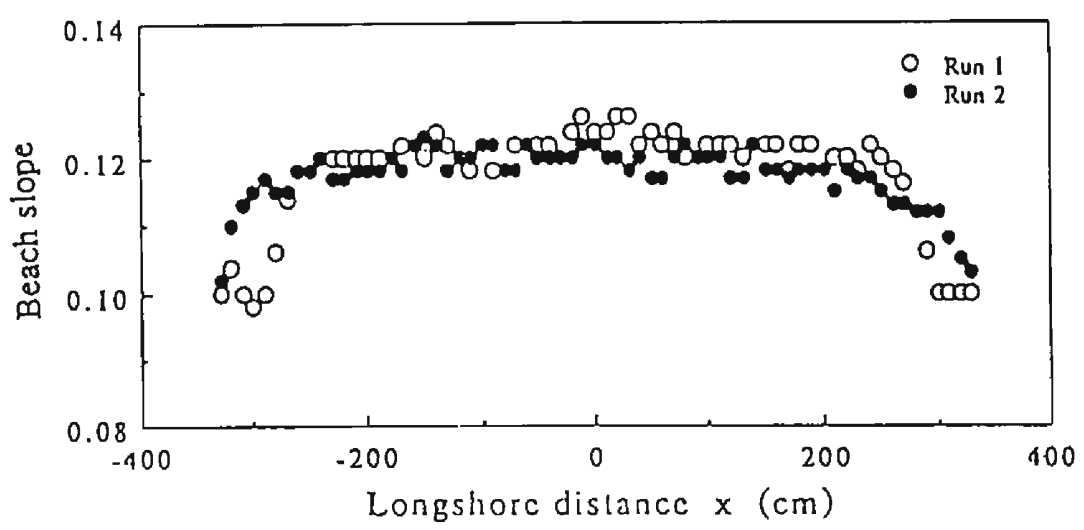

(a) In the case of Series $\mathrm{A}$

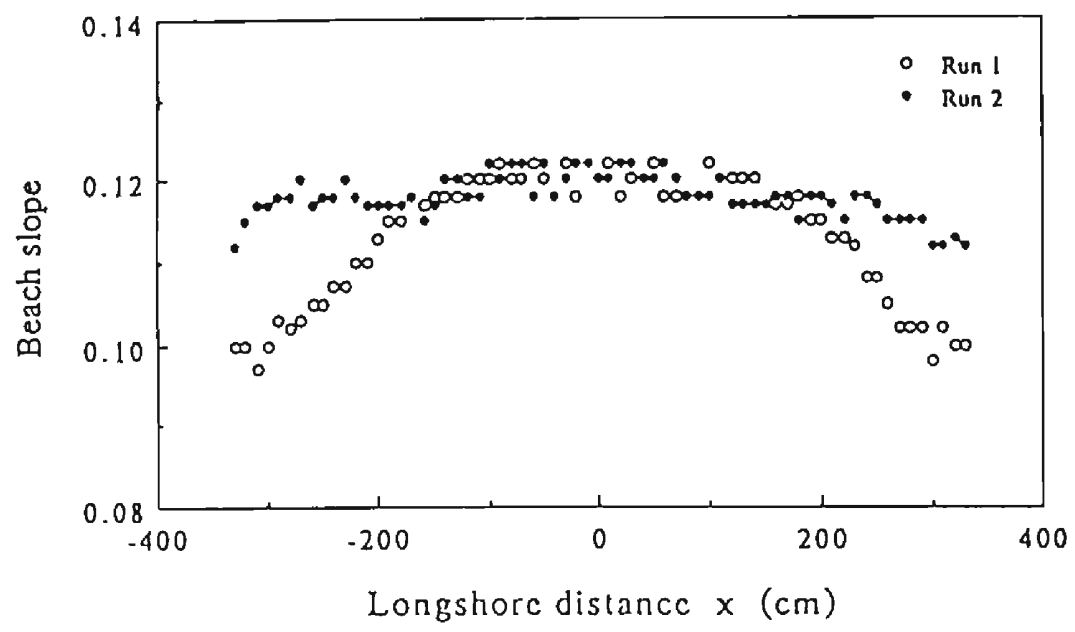

(b) In the case of Series $B$

Fig. 19. Longshore changes in beach slope at the shoreline along the river deltas.

currents. In the case of normal wave incidence as shown in Fig. 20(a), it is obvious that the data measured for Run $A-2$ are to be continuous to those for Run A-1, which is expected since the rate of sediment input was kept constant during the experiments. While, in the case of normal wave incidence shown in Fig. 20(b), the data measured for Run B-2 are plotted above those for Run B-1, the data fluctuate around the mean values while they are increasing linearly. This behavior in the measured data of this figure is probably due to the nonuniformity of longshore sediment transport. In the case of oblique wave incidence, on the contrary, Fig. 20(c) illustrates the relationship between $A$ and $y_{0}$ for Run $\mathrm{C}-1$ and Run $\mathrm{D}-1$ where the angles of wave incidence are $7.5^{\circ}$ and $15^{\circ}$, respectively. Although the measured data are scattered, the general trend is linear. 


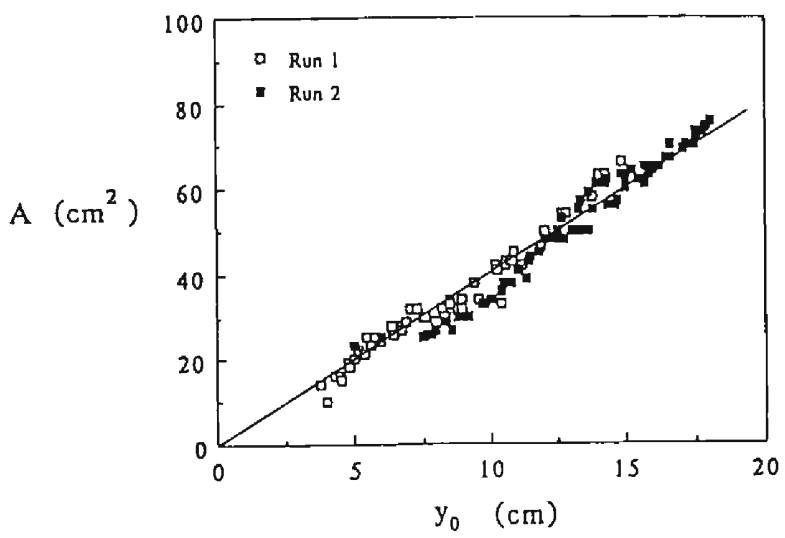

(a) In the case of Series A (normal wave incidence)

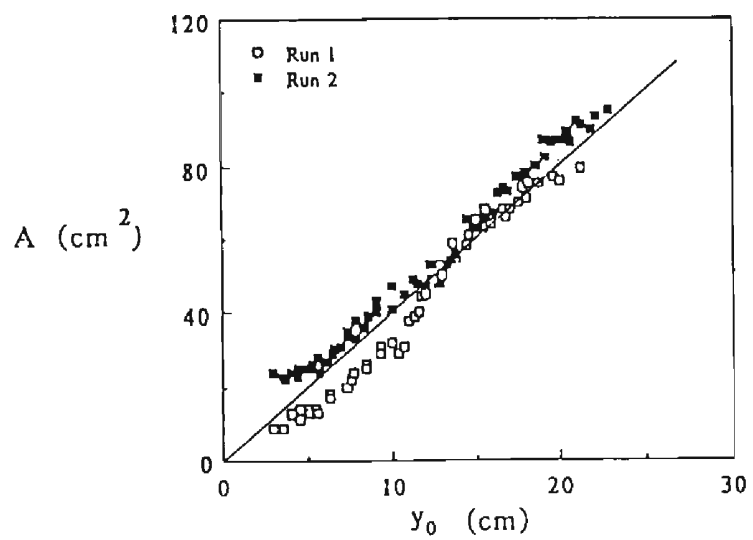

(b) In the case of Series B (normal wave incidence)

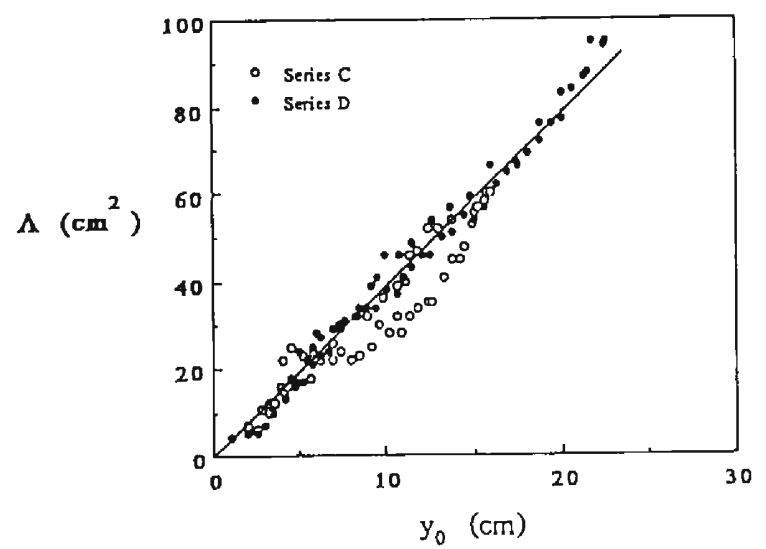

(c) In the cases of Series C and D (oblique wase incidence)

Fig. 20. Relations between the cross sectional area of beach profiles and the shoreline change from the datum line. 


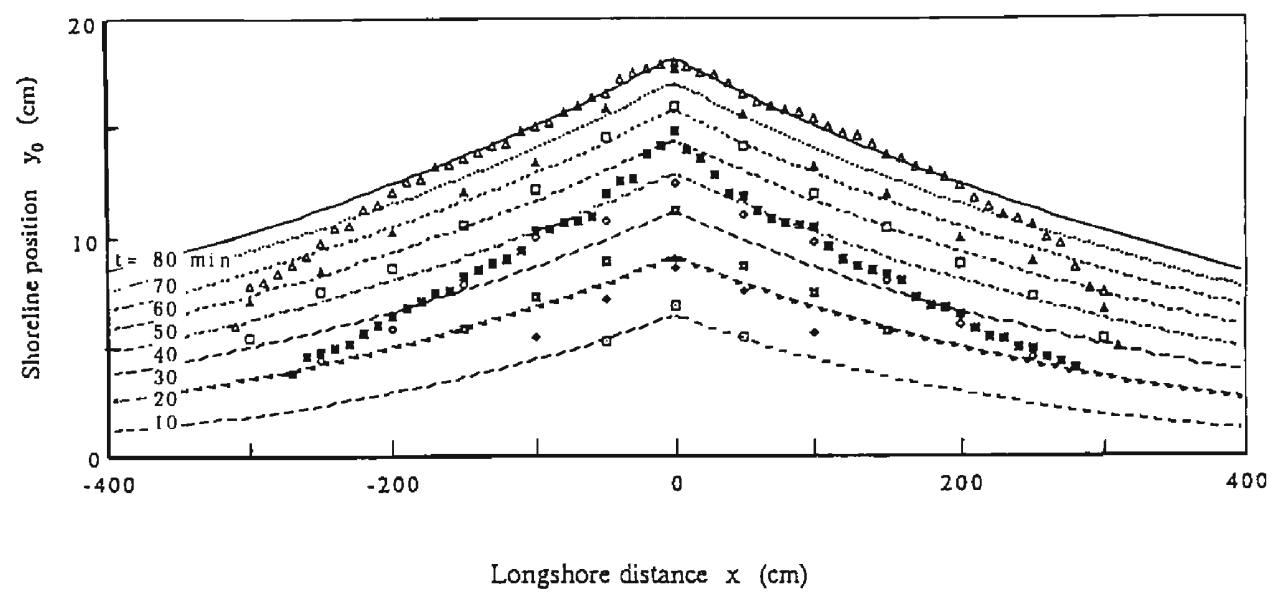

Fig. 21. Comparison between theoretical and experimental shorelines in the formation process of a river delta.

Thus, it may be argued that the oblique angles of incoming waves have no effect on the relationship.

\section{(4) Applicability of theoretical solutions to experiments}

The measurements of shoreline evolution of a river delta for experimental runs A-1 and $\mathrm{A}-2$ are compared with the theoretical solution given by Eq. (18), the results are shown in Fig. 21. In the comparison all the experimental parameters in Eqs. (12) and (13) must be determined experimentally, but in this comparison, using the rate of sediment input, $q_{R}$ and the limiting water depth for littoral drift, $h_{k}$ and the shoreline positions at $t=0 \mathrm{~min}$ and $80 \mathrm{~min}$, the values of $\varepsilon_{1}$ and $\varepsilon_{2}$ were estimated to fit the theoretical curve of shoreline with that of the experiment at $t=80 \mathrm{~min}$. It is seen from the comparison that the evolution of the shoreline near the river mouth is well predicted. However, near the longshore ends of the river delta less agreement between the measured and computed shoreline position is observed. This may be due to the effect of the roughness of fixed bed in the wave tank, which induced rapid transport of the sediment downcoast, causing the shoreline to rapidly decrease.

In Fig. 17(a), the time variation of shoreline positions at the measuring sections has been compared with the theoretical solution. As previously mentioned, a good prediction between the measured and the computed shoreline was observed for the measuring sections near the river mouth. At the end side of the river, represented by section 6 , the evolution of shoreline by theoretical solution was overestimated. In further application of the theoretical solutions to the prediction of shoreline change in the formation process of river deltas, it is, of course, necessary to specify all the empirical parameters in the solutions universarily. However, when the formula of longshore sediment transport and the limiting water depth for littoral drift are established, all the parameters can be determined. 


\section{2 Experiments on Reduction Process of River Deltas}

The protection of beaches against erosion is one of the important problems which coastal engineers must face, especially near river mouths and adjacent coasts. In order to prevent erosion of the coast of river delta, it is important to study the reduction process of river delta which is one of the beach erosive processes and whose general behavior in the field coast is very difficult to investigate. Therefore, laboratory experiments must be relied upon. By hydraulic experiments, if the similitude of the hydraulic experiment is established, it is possible to simulate a hundred year prototype phenomenon in only few hours in laboratory by controlling the experimental conditions and measurements. Beach erosion in the coast of river delta mainly occurs due to decrease or lack of longshore sediment transport by coastal structures and sediment sources from the river. When neither the longshore currents and longshore sediment transport exist along the beach, in other words, when predominant waves approach normally for a sufficiently long time, the beach plane shape and profiles will be in equilibrium. Introducing the basic idea that the beach profile in equilibrium dissipates incident wave energy without significant net change in shape, Dean (1977) derived an empirical expression for the equilibrium beach profile. The main objectives of this experimental study are to investigate the reduction process of river deltas, to examine the time variation of shoreline positions and the rate of beach erosion, and finally, to verify the relationship between shoreline position and crosssectional area of the reduced beach profile.

\section{(1) Experimental procedure}

The initial shoreline and beach profile in this experiment simulated the final ones in the experiment of the formation process of river delta presented in the previous section, (Series A and B). An experiment was halted once no remakable longshore current existed, with only cross-shore movement. To verify this condition, color tracers were used and the trajectories were observed. Measurements of shoreline changes were made in the same way as in the formation process of river delta.

\section{(2) Experimental results}

Two experiments were performed as cases A-3 and B-3, as shown in Table 1, with a still water depth of $30 \mathrm{~cm}$, a wave height of $2.0 \mathrm{~cm}$ and a wave period of $0.8 \mathrm{sec}$. The incoming waves were normally incident during the experiments.

a) General description of river delta reduction process The reduction process of river deltas is significantly different from the formation process of river deltas. By the experiment it was observed that 1) In general the coast of river delta significantly is eroded due to the decrease or lack of sediment input, while the submerged slope, which is located out side the surf zone, in front of the delta retreats shoreward at a very slow rate. This phenomenon occurs because the breaking waves more strongly affect the shoreline than the submerged slope., 2) The sediments move alongshore from the river mouth area and deposit at the longshore ends of the river delta, and as a result, a nearly straight shoreline is finally formed near the middle of the deltaic area., and 3) The rate of longshore sediment transport decreases as the shoreline becomes nearly straight. The 
Table 1. Experimental conditions of formation and reduction processes of river delta.

\begin{tabular}{|c|c|c|c|c|}
\hline Run & No. & $Q_{R} \mathrm{~cm}^{3} / \mathrm{sec}$ & Run time (min) & $\alpha_{0}$ (deg.) \\
\hline \multirow{2}{*}{ Series A } & A-1 & 7.06 & 50 & 0 \\
& A-2 & 7.06 & 30 & 0 \\
Series B & B-1 & 15.08 & 30 & 0 \\
& B-2 & 8.12 & 30 & 0 \\
Series C & C-1 & 11.0 & 90 & 1.5 \\
Series D & D-1 & 11.0 & 180 & 15.0 \\
\hline
\end{tabular}

cross-shore sediment movement becomes then predominant, upon which the beach profile reaches equilibrium, finally stabilizing its form.

b) Characteristic of reduction of river delta Fig. 22 shows the process of river delta reduction for Series A-3 and B-3. Due to the lack of sediment input, the shoreline of the delta rapidly becomes nearly straight, resulting in erosion near the center of river delta and deposition near the longshore ends of the river delta. It is noted that the new shoreline position in Fig. 22(a) is shown more shoreward than the shoreline position in

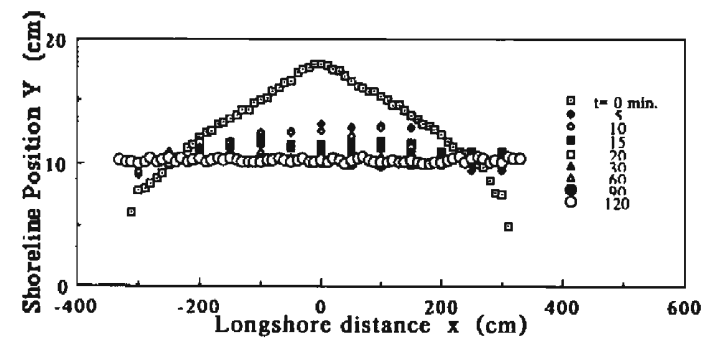

(a) In the case of Series $A-3$

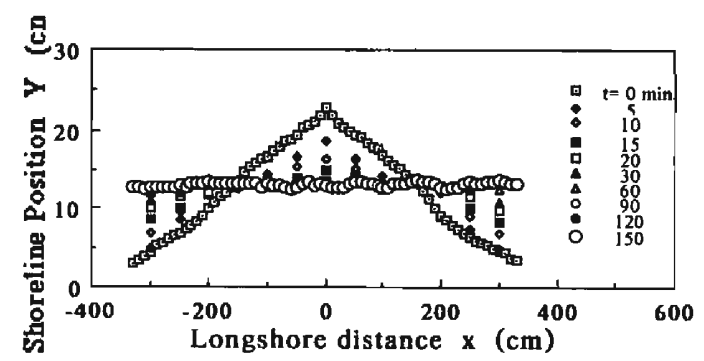

(b) In the case of Series $\mathbf{B}^{-3}$

Fig. 22. Time variation of shoreline change in the reduction process of river delta. 


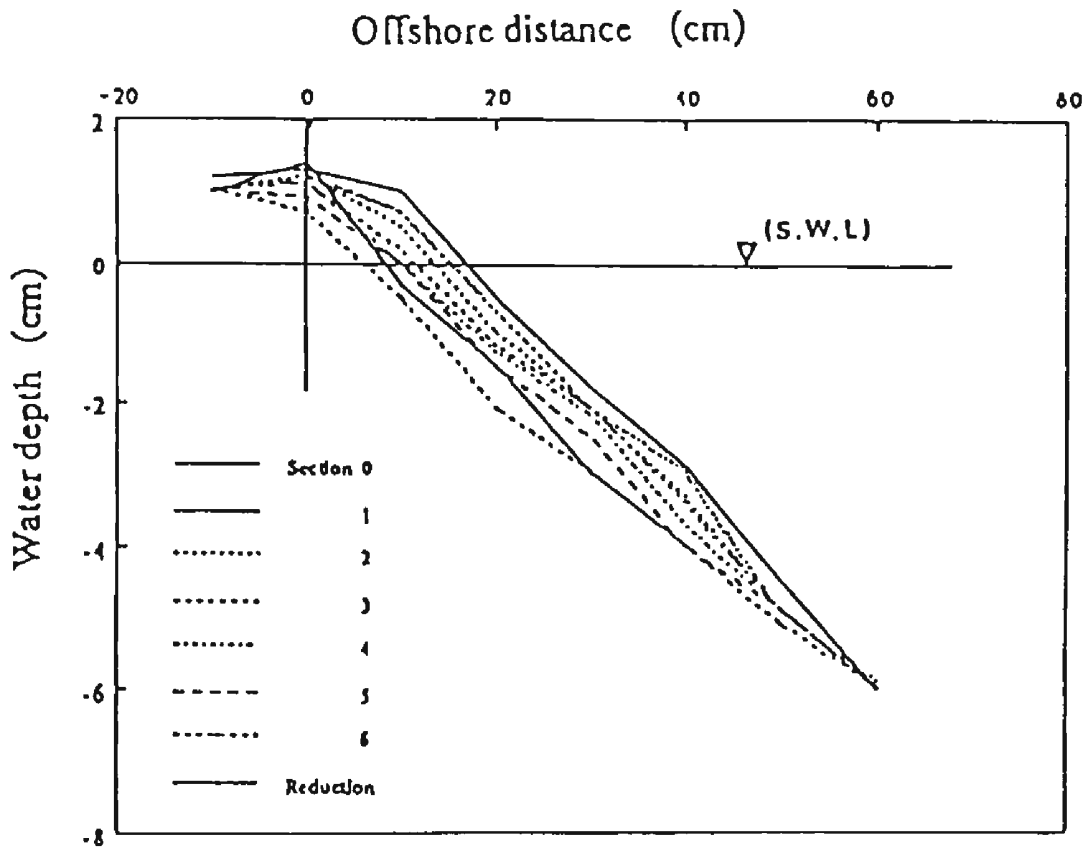

(a) In the case of Series $\mathrm{A}-3$

OlTshore dislance $(\mathrm{cm})$

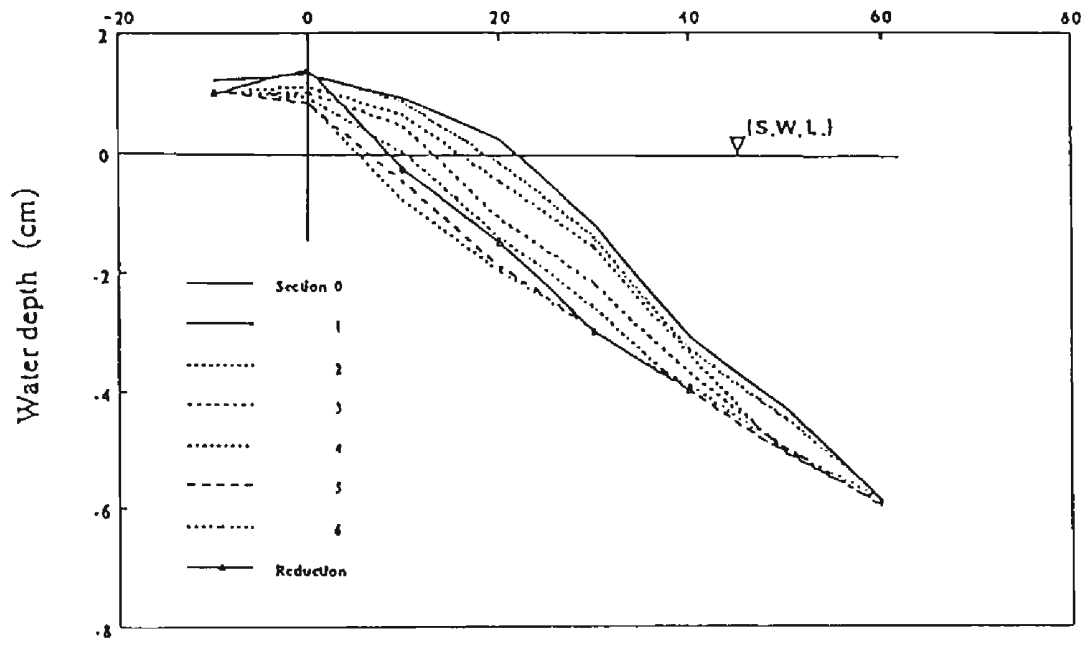

(b) In the case of Series $B^{-}-3$

Fig. 23. Time variation of shoreline change at several positions in the reduction process of river delta. 


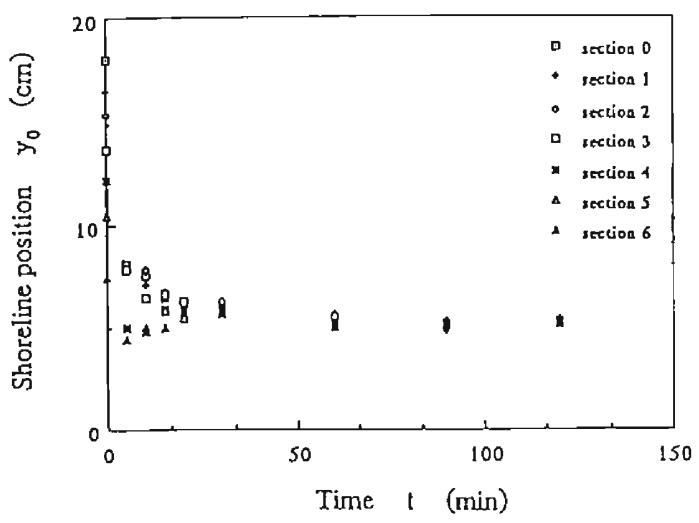

(a) In the case of Series $A_{-3}$

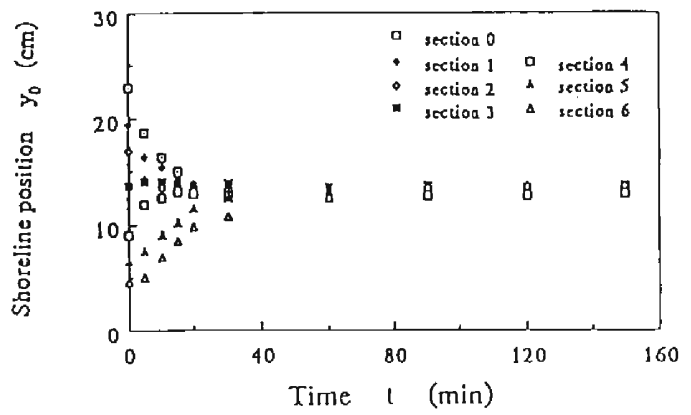

(b) In the case of Series $\mathrm{B}-3$

Fig. 24. Changes in beach profile in the reduction process of river delta in comparison with those in the formation process.

Fig. 22(b), that is because the total sediment volume for Series A-3 was smaller than that for Series B-3, while the wave conditions were the same in both experiments.

c) Time variation of shoreline positions and beach profiles The time variation of the shoreline positions at selected sections for Series A-3 and B-3, is shown in Fig. 23(a) and (b), respectively. It is noted from the figure that; 1) the shoreline position at the center of the river delta decreases significantly with increasing time $t$, while the shoreline position at the end of river delta increases, and 2) the physical process of erosion at the center of the river delta and accretion at the longshore end sides of the river delta occurs rapidly, followed by a nearly constant shoreline position.

The beach profiles were measured every $10 \mathrm{~cm}$ along the shoreline. The measurements revealed that the beach profiles along the river delta are nearly similar in shape. Fig. 24 illustrates the change of beach profiles in the reduction processes of river delta, by comparing it with that in the formation process. It is noted that the beach profile changes from a convex type which was shown in the formation process to a concave one. This phenomenon is completely different from the formation process, and may be due to 


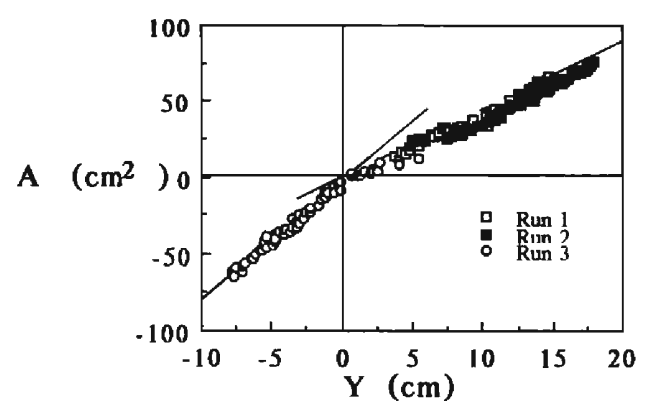

(a) In the case of Run $A^{-3}$

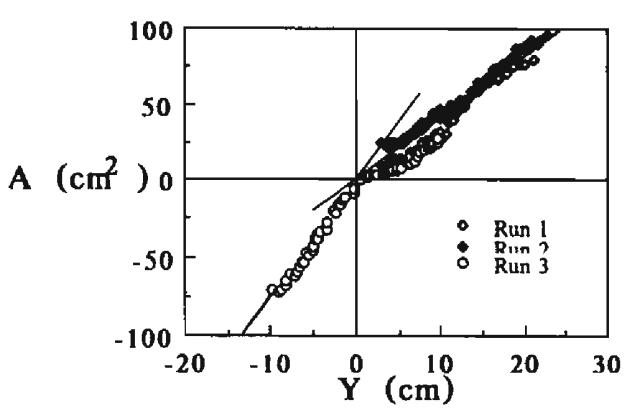

(b) In the case of Run B-3

Fig. 25. Relation between the cross sectional area of beach profiles and the shoreline change from the datum line.

the rapid erosion in the surf zone to maintain the longshore sediment transport by waves.

d) Relationship between shoreline position and cross-sectional area The cross-sectional area between two beach profiles was measured every $10 \mathrm{~cm}$ interval along the shoreline in order to exmine the assumption of beach profile in the one-line theory of shoreline change as discussed above. Fig. 25 shows the relation between the cross sectional area in beach profiles and the shoreline positions in comparison with that in the formation process. It is noted from the compariosn that the relationship between the cross-sectional area and the shoreline position is nearly linear, like the formation process of river delta, but the gradient of the relation in the reduction process is larger than that in the formation process. This is due to the change in beach profiles from convex to concave as discussed above.

\section{Conclusions}

The formation and reduction processes of river deltas have been investigated theoretically and experimentally in this paper. The formation and reduction processes are governed by the relation between the rates of sediment input from rivers and longshore sediment transport by waves and currents. By use of the equations of longshore sediment transport under unsteady, nonuniform conditions and the equation of continuity of beach change, the linearized equations of the formation and reduction processes as well as shoreline change are first derived, and secondly, introducing the longshore change in breaker water depth into the equation of longshore sediment transport, the linearized equations of the formation and reduction processes of river deltas were obtained as an improvement of the usual equations based on the concept of one-line theory. Applying the second one, theoretical solutions to shoreline changes in the formation and reduction processes of river deltas were obtained. From the results of the theoretical solutions, the following conclusions can be drawn :

(1) The solutions of formation process of river deltas of infinite and finite river 
mouth widths were obtained from the linearized equations of shoreline change. It was theoretically found that the configuration of river delta becomes asymmetric when the dimensionless quantity $\varepsilon_{1} a / \varepsilon_{2}$ is greater than zero, and the degree of asymmetrical configuration of the river delta becomes highly significant as the quantity $\varepsilon_{1} a / \varepsilon_{2}$ increases, which implies that as the incident wave angle increases, the asymmetrical configuration of the river delta becomes significantly remarkable. It was also obvious from the theory that the shoreline gradient, $\left|\partial y_{0} / \partial x\right|$, becomes larger with an increase of $\varepsilon_{1} a / \varepsilon_{2}$, which means that increasing the rate of beach slope change along the river delta causes the shape of river delta to be distinctly formed.

(2) By normal wave incidence, the reduction of the river delta takes place symmetrically with respect to the center of the river. The shoreline at the vicinity of the river mouth is rapidly eroded, while the shorelines at the longshore ends of the river delta retreat slowly. At the final stage, the configuration of the river delta may become a straight beach. By oblique wave incidence, the reduction of the river delta takes place asymmetrically, at a faster rate of reduction on the upcoast side of the delta than on the downcoast side. Also, the river mouth moves predominantly in the direction of littoral drift, as the reduction process of river delta takes place.

In order to understand the physical processes of formation and reduction processes of river deltas, and to compare the results of the formation process with the theoretical one, experiments on the formation and reduction processes of river deltas were carried out. The following conclusions can be drawn from the experiments:

(1) For the wave-dominated delta, the shoreline of river delta propagates at nearly the same rate as the propagation of the submerged front line of the delta, while for the river-dominated delta, the shoreline of the delta propagates at a faster rate than the submerged front line of the delta. In the formation process of a river delta, the crosssectional area of beach profile is proportional to the change of shoreline position and its proportional coefficient is practically equal to the limiting depth for littoral drift. Therefore, the one-line theory of shoreline change can be used to describe long term variations in shoreline configuration during river delta formation.

(2) For the wave-dominated delta type, the longshore variation of beach slope is very small with a gently mild beach profile. The shoreline gradient changes gradually, resulting in gently curving river delta shape. On the contrary, for the river-dominated delta type, beach slope remarkably varies along the delta coast with steeper shopes at the river mouth and milder ones at the longshore end sides of the delta. The shoreline gradient varies resulting in a sharply curved shape delta.

(3) Since the waves approach the shoreline obliquely, the longshore sediment transport is predominant. Consequently, most of the sediment moves in the predominant direction of littoral drift. As a result, the reduction rate of the shoreline on the upstream coast side is greater than the reduction rate of the shoreline on the downcoast. Also, the river mouth changes in shape in the predominant direction of littoral drift. The final stage for the configuration of the delta may be an inclined straight beach where the waves tend to approach it normally. 
(4) In comparison, all the experimental parameters in the theoretical solutions must be determined experimentally. However, using the rate of sediment input, $q_{R}$ and the limiting water depth for littoral drift, $h_{k}$ and the shoreline positions at $t=0 \mathrm{~min}$ and 80 min, the values of $\varepsilon_{1}$ and $\varepsilon_{2}$ were estimated to fit the theoretical curve of shoreline with that of experiment at $t=80 \mathrm{~min}$. It was concluded from the comparison that the evolution of the shoreline near the river mouth is well-predicted, and that the time variation of shoreline positions is also predicted satisfactorily. In further application of the theoretical solutions to the prediction of shoreline change in the formation process of river deltas, it is of course necessary to specify all the empirical parameters in the solutions universally, but when the formula of longshore sediment transport and the limiting water depth for littoral drift are established, all the parameters can be detemined.

(5) In the reduction process, the shoreline of the delta is rapidly eroded while the submerged front line of the river delta retreats at a very slow rate, while in the formation process, both the shoreline and the submerged front line of the delta propagate at the same rate. It was noted in the reduction process that the beach profile changes from a convex type, which was shown in the formation process, to a concave-upward one. This fact is completely different from the formation process, and may be due to the rapid erosion in the surf zone to maintain the longshore sediment transport by waves.

(6) It was noted in the reduction process that the relationship between the crosssectional area and the shoreline position is nearly linear, like the formation process of river delta, but the gradient of the relation in the reduction process is larger than that in the formation process. This is due to the change in beach profiles from a convex type to concave one as discussed above. After a sufficiently long time, the beach profile reaches a stable shape which is called the equilibrium beach profile.

Finally, further extension of the present study should be directed towards both theoretical investigations of relationship between the formation and reduction processes as one of diffusion processes and beach erosion around the river deltas as one of kinematic waves, and the practical applications of the concept of formation and reduction processes of river deltas. Since the bases of this concept have already been established, it is still possible to develop even better understanding and better control of the processes of formation and reduction of river deltas, which is the task of the near future.

\section{Acknowledgements}

We appreciate the kind cooperation of Associate Professor Y. Kawata in the experimental study on the formation and reduction processes of river deltas, and Mr. S. Fujiki, Technical Officer, for his kind assistance in the arrangement of measuring equipment of the experiment. Part of this investigation was funded by a Grant -in-Aid for Scientific Research (No. 01850121) from the Ministry of Education, Science \& Culture of Japan.

\section{REFERENCES}

Abramowitz, M. and Stegun, I. A., 1972, Handbook of Mathematical Functions, 9th ed., Dover Pub. Inc., New York. 
Bakker, W. T., 1968, The dynamics of a coast with a groin system, Proc. 11th Coast. Eng. Conf., ASCE, pp. 492-517.

Bakker, W. T. and Edelman, T., 1964, The coastline of river deltas, Proc. 9th Coast. Eng. Conf., ASCE, pp. 199-218.

Carslaw, H. and Jaeger, J., 1959, Conduction of Heat in Solids, 2nd ed., Clarendon Press, Oxford.

Dean, R. G., 1973, Heuristic models of sand transport in the surf zone, Proc. Australian Conf. on Coast. Eng., pp. 208-214.

Dean, R. G., 1977, Equilibrium beach profiles, US Atlantic and Gulf Coastal, Ocean Engineering, Report No. 12, University of Delaware Press.

Dean, R. G., 1984, CRC Handbook of Coastal Processes and Erosion, by Komar, P. D., CRC Press Inc., Boca Raton.

Grijm, W., 1961, Thoretical forms of shoreline, Proc. 7th Coast. Eng. Conf., ASCE, pp. 197-202.

Grijm, W., 1964, Theoretical forms of shorelines, Proc. 9th Coast. Eng. Conf., ASCE, pp. 219-235.

Hanson, H. and Larson, M., 1987, Comparison of analytic and numerical solutions of the one-line model of shoreline change, Proc. Coast. Sed. '87, ASCE, pp. 500-514.

Iwagaki, Y., 1966, A treatise on beach erosion, Summer Seminar on Hyd. Eng., JSCE, B-17. 1-17. 17 (in Japanese).

Komar, P. D., 1973, Computer models of delta growth due to sediment input from waves and longshore transport, Geolog. Soc. America Bull., Vol. 84, pp. 2217-2226.

Kraus, N. C., Hanson, H. and Harikai, S., 1985, Shoreline change at Oarai beach-Past, present and future, Proc. 19th Coastal Eng. Conf., ASCE, pp. 2107-2123.

Kreyzing, E., 1983, Advanced Engineering Mathematics, 5th ed., John Wiley \& Sons, Inc., Canada.

Le Méhauté, B. and Brebner, A., 1961, An introduction to coastal morphology and littoral processes, Report No. 14, Civil Eng. Dept., Queens University at Kingston, Canada.

Le Méhauté, B. and Soldate, M., 1979, Mathematical modeling of shoreline evolution, Proc. 16th Coast. Eng. Conf., ASCE, pp. 1163-1179.

Pelnard-Considére, R., 1956, Essai de l'evolution des froms de rivage en plage de sable et de galets, 4th Jour. de 1'Hyd., des Energ. de la Mar, Que. III, No. 1, pp. 289-298.

Price, W. A., Tomlinson, D. W., and Willis, D. H., 1972, Predicting changes in the plan shape of beaches, Proc. 13th Coast. Eng. Conf., ASCE, pp. 1321-1329.

Sasaki, T. O. and Sakuramoto, H., 1978, Field verification of a shoreline simulation model, Inter. Conf. on Water Res. Eng., IAHR, pp. 501-518.

Tsuchiya, Y., 1973, Coastal sediment balance and beach change, Summer Seminar on Hyd. Eng., JSCE, pp. B-3. 1-3. 19 (in Japanese).

Tsuchiya, Y., 1978, Beach erosion and its prediction, Annuals, D. P. R. I., Kyoto University, No. 21A, pp. 1-18 (in Japanese).

Tsuchiya, Y. and Refaat, H., 1992, Nonuniform longshore currents; Theory and experiments, Jour. Water., Port, Coast. \& Ocean Eng., ASCE, 1991 (in review).

Tsuchiya, Y. and Yasuda, T., 1979, A mathematical model for beach change, Proc. 25th Japanese Conf. on Coast. Eng., JSCE, pp. 36-40 (in Japanese).

Walton, T. and Chiu, T., 1979, A review of analytical techniques to solve the sand transport equation and some simplified solutions, Proc. Coast. Struct. '79, ASCE, pp. 809-837. 